Clinical Science: this is an Accepted Manuscript, not the final Version of Record. You are encouraged to use the Version of Record that, when published, will replace this version. The most up-to-date version is available at http://dx.doi.org/10.1042/CS20171221. Please cite using the DOI $10.1042 /$ CS20171221

\title{
TRAIL reduces impaired glucose tolerance and NAFLD in the high-fat diet-fed
}

\section{mouse}

Stella Bernardi ${ }^{1}$, Barbara Toffoli ${ }^{2}$, Veronica Tisato ${ }^{3}$, Fleur Bossi ${ }^{1}$, Stefania Biffi ${ }^{2}$, Andrea Lorenzon ${ }^{4}$, Giorgio Zauli ${ }^{3}$, Paola Secchiero ${ }^{3}$, Bruno Fabris ${ }^{1}$

${ }^{1}$ Department of Medical Sciences, Università degli Studi di Trieste, Cattinara Teaching Hospital,

Strada di Fiume 447, 34100 Trieste

${ }^{2}$ Institute for Maternal and Child Health, IRCCS “Burlo Garofolo”, via dell’Istria 65, 34137 Trieste,

Italy

${ }^{3}$ Department of Morphology, Surgery and Experimental Medicine and LTTA Centre, Università degli

Studi di Ferrara, Via Fossato di Mortara 66, 44100 Ferrara

${ }^{4}$ Cluster in Biomedicine, CBM S.c.r.1., Area Science Park, Trieste, Italy

Word count: 4011

Corresponding author:

7 Stella Bernardi MD, PhD

8 Department of Medical Sciences, Università degli Studi di Trieste, Cattinara Teaching Hospital, Strada

di Fiume 447, 34100 Trieste, Italy

E: stella.bernardi@asuits.sanita.fvg.it/shiningstella@gmail.com

P: (+39)3339534214 / (+39)0403994236

F: (+39)0403994493 
Aims/hypothesis: Recent studies suggest that a circulating protein called TRAIL (TNF-related apoptosis-inducing ligand) may have an important role in the treatment of type 2 diabetes. It has been shown that TRAIL deficiency worsens diabetes and that TRAIL delivery, when it is given before disease onset, slows down its development. This study aimed at evaluating whether TRAIL had the potential not only to prevent, but also to treat type 2 diabetes.

Methods: Thirty male C57BL/6J mice were randomized to a standard or a high-fat diet (HFD). After 4 weeks of HFD, mice were further randomized to receive either placebo or TRAIL, which was delivered weekly for 8 weeks. Body weight, food intake, fasting glucose and insulin were measured at baseline and every 4 weeks. Tolerance tests were performed before drug randomization and at the end of the study. Tissues were collected for further analyses. Parallel in vitro studies were conducted on HepG2 cells and mouse primary hepatocytes.

Results: TRAIL significantly reduced body weight, adipocyte hypertrophy, free fatty acid levels and inflammation. Moreover, it significantly improved impaired glucose tolerance, and ameliorated non-

37 alcoholic fatty liver disease (NAFLD). TRAIL treatment reduced liver fat content by $47 \%$ in vivo as 38 well as by $45 \%$ in HepG2 cells and by $39 \%$ in primary hepatocytes. This was associated with a 39 significant increase of liver PGC-1 $\alpha$ expression both in vivo and in vitro, pointing to a direct protective 40 effect of TRAIL on the liver.

41 Conclusion/interpretation: This study confirms the ability of TRAIL to attenuate significantly diet42 induced metabolic abnormalities, and it shows for the first time that TRAIL is effective also when 43 administered after disease onset. In addition, our data sheds light on TRAIL therapeutic potential not 44 only against impaired glucose tolerance, but also against NAFLD. 
45 Keywords: high-fat diet, impaired glucose tolerance, type 2 diabetes, NAFLD, NASH, mouse model, TRAIL, PPAR $\gamma$, PGC- $1 \alpha$.

\section{Abbreviation list}

48 AOX, Acyl-CoA oxidase; ATG7, autophagy-related protein 7; CPT carnitine palmitoyl transferase;

49 CPT1a, carnitine palmitoyl transferase-1a; CRP, C-reactive protein; CYT SYNT, cytrate synthase; FAS 50 fatty acid synthase; gp91phox is a subunit of NADPH oxidase; HFD, high-fat diet; IPITT, 51 intraperitoneal insulin tolerance test; HNF4, hepatocyte nuclear factor 4; MCP1, monocyte 52 chemoattractant protein-1; NAFLD, non-alcoholic fatty liver disease; NASH, non-alcoholic 53 steatohepatitis; PGC-1 $\alpha$, peroxisome proliferator-activated receptor- $\gamma$ coactivator-1 alpha; pgWAT, 54 perigonadal white adipose tissue; PLN5, perilipin 5; PPAR $\alpha$, peroxisome proliferator-activated receptor- $\alpha$; PPAR $\gamma$, peroxisome proliferator-activated receptor- $\gamma$.; SIRT1, sirtuin-1; SREBP1a, sterol

56 regulatory element binding protein-1a; SREBP1c, sterol regulatory element binding protein-1c;

57 TRAIL, TNF-related apoptosis-inducing ligand; UCP2, uncoupling protein. 
TRAIL is an acronym for TNF-related apoptosis-inducing ligand, which is a circulating protein

61 belonging to the TNF superfamily. Like other members of this family, such as FasL and TNF $\alpha$, TRAIL

62 has the ability to induce programmed cell death (apoptosis). However, as compared to them, TRAIL

63 hits preferentially transformed cells, such as cancer cells, while sparing the normal ones (1). In non-

64 malignant cells, TRAIL actions remain largely unexplored.

65

66

67

68

69

70

71

72

73

Recent experimental evidence suggests that TRAIL has significant metabolic effects $(2,3)$, and might be involved in the regulation of obesity and diabetes mellitus, as well as their complications. The first studies reporting TRAIL beneficial effects on diabetes were carried out in models of type 1 diabetes and showed that TRAIL attenuated disease development and progression $(4,5)$ with partial preservation of islet morphology (6). More recently, we reported that TRAIL delivery significantly reduced the metabolic abnormalities of an experimental model of type 2 diabetes (7). Consistent with these observations, other groups have shown that genetic lack of TRAIL worsened both forms of diabetes and their associated diseases (8), such as atherosclerosis (8) and non-alcoholic fatty liver disease (NAFLD) (9).

The high-fat diet (HFD)-fed mouse is one of the models suitable for the study of type 2 diabetes (10). After a few weeks, the HFD usually increases body weight and fat mass, leading to peripheral insulin resistance and impaired glucose tolerance, with subsequent hyperglycemia and hyperinsulinemia (10). Although the HFD-fed mouse does not always develops diabetes, but rather impaired glucose tolerance, it has the advantage of reproducing the human situation more accurately than genetic models of obesity-induced diabetes (11). Moreover, it allows for the study of common and burdensome diabetic comorbidities, such as obesity, NAFLD, and non-alcoholic steatohepatitis (NASH) (12). 
81 A few years ago, we reported that TRAIL significantly ameliorated the metabolic abnormalities of the 82 HFD-fed mouse. In that paper, TRAIL treatment was started before the development of metabolic 83 abnormalities, following a preventive treatment schedule. In this study, we aimed at evaluating the 84 therapeutic potential of TRAIL against type 2 diabetes. For this reason, TRAIL treatment was started 85 after the development of metabolic abnormalities, following a therapeutic schedule. Here we report the 86 effects of TRAIL treatment on glucose tolerance and on the tissues regulating it. 


\section{Recombinant human TRAIL (rhTRAIL)}

Recombinant histidine 6-tagged human TRAIL (114-281) was produced in transforming bacteria BL21 with a pTrc-His6 TRAIL vector, as described (13) and detailed in the Supplementary Material and Methods.

\section{Experimental protocol}

As reported in Figure 1A, thirty 8-week-old C57BL/6J male mice (Harlan Laboratories, Udine, Italy) were randomized to receive either a standard diet $(\mathrm{CNT}, \mathrm{n}=10)$ or a high-fat diet $(\mathrm{HFD}, \mathrm{n}=20)$ for 12 weeks. After 4 weeks from diet randomization, HFD mice were randomly allocated to receive either saline (HFD, $n=10)$ or rhTRAIL (HFD + TRAIL, $n=10$ ) for the remaining 8 weeks. CNT mice received saline $(\mathrm{NaCl} 0.9 \%)$ as well. rhTRAIL (TRAIL) was given at a dose of $10 \mu \mathrm{g} / 200 \mu \mathrm{L}$ per mouse by weekly intraperitoneal (IP) injection. Standard diet provided $22 \%$ of calories from protein, $66 \%$ of calories from carbohydrate, and $12 \%$ of calories from fat, and a digestible energy of $3.0 \mathrm{Kcal} / \mathrm{g}$ (Tekland Global 16\% Protein Rodent Diet, Harlan Laboratories). HFD provided 18.4\% of calories from protein, $21.3 \%$ of calories from carbohydrate, and $60 \%$ of calories from fat, and a digestible energy of 5.1 Kcal/g (TD 06.414 Adjusted calories diet 60/fat, Harlan Laboratories). Animals were kept (5/cage) in ventilated cabinets (Tecniplast Spa, Buggiate, Varese, Italy), in specific-pathogen-free and temperature-controlled rooms $\left(22^{\circ} \mathrm{C}\right)$, with relative humidity of $50-70 \%$, on a $12 \mathrm{~h} \mathrm{light} / 12 \mathrm{~h}$ dark cycle. They had free access to food and water, and they were fed ad libitum for the length of the study. During the 12-week study period, body weight, food intake, glucose, and insulin were measured at baseline and at 4-week intervals. Tolerance tests were performed before drug randomization and at the end of the study. At the end of the study, animals were anesthetized by an IP injection of tiletamine/zolazepam 
$111(80 \mathrm{mg} / \mathrm{kg})$. Blood was collected from the left ventricle, centrifuged, and serum was stored for further 112 analyses (total cholesterol, HDL cholesterol, triglycerides, free fatty acids, C-reactive protein). 113 Pancreas, perigonadal white adipose tissue (pgWAT), liver, and quadriceps were weighed and either 114 snap frozen or fixed in formalin for further analyses.

115 The Guide for the Care and Use of Laboratory Animals, 8th edition (2011), as well as specific 116 European (86/609/EEC) and Italian (D.L.116/92) laws were followed. In compliance with the principle 117 of reducing as much as possible the number of mice studied, we did not include CNT mice + TRAIL 118 because we have previously observed and reported that repeated injections of TRAIL (providing a 119 cumulative dose of $100 \mu \mathrm{g} /$ mouse) did not affect glucose, insulin, and/or body weight in normal 120 conditions in vivo (6). This study was approved by the Institutional Animal Care and Use Committee of 121 the Cluster in Biomedicine (CBM) and by the Italian Ministry of Health (DM 17/2001 A dd. 122 02/02/2011). The study period was June 2015-May 2017.

\section{Assessment of TRAIL biodistribution}

124 In order to evaluate TRAIL bioavailability when delivered by IP injection, 20-week-old C57BL/6J 125 male mice $(\mathrm{n}=3)$ received $10 \mu \mathrm{g}$ of Cy5.5-TRAIL by IP injection, and fluorescence in the peritoneal 126 cavity was acquired at baseline and after 30 minutes, 6 hours, and 30 hours post-injection, as 127 previously reported (14). The details of TRAIL labeling are in the Supplementary Materials and 128 Methods. In addition, 20-week-old C57BL/6J male mice ( $\mathrm{n}=8)$ received $10 \mu \mathrm{g}$ of TRAIL by IP 129 injection, bloods were collected at baseline and after 6, 30, 48, and 72 hours, and TRAIL was measured 130 by ELISA (R\&D; \#DTLR00).

\section{General parameters and biochemistries}


Food intake was measured by placing in the cages pellets previously weighed in total. The food that 133 was left over was collected and weighed to find the amount eaten. Energy intake was measured 134 according to the digestible energy provided by both diets. Fasting glucose was measured by glucometer 135 (Glucomen LX Plus, Menarini). Fasting insulin was measured by ELISA (Millipore; \#EZRMI-13K). 136 NEFA concentrations were measured by colorimetric assay (Sigma; \#MAK044-1KT). Circulating total 137 cholesterol, HDL cholesterol, and triglycerides were measured with the AU5800 analyzer (Beckman 138 Coulter) by enzymatic colorimetric method, while C-reactive protein (CRP) was measured by 139 immunoturbidimetric method.

\section{Tolerance tests}

141 The intraperitoneal glucose tolerance test (IPGTT) was performed on day 1 of week 4 and week 12 by 142 injecting glucose $(2 \mathrm{~g} / \mathrm{kg})$ intraperitoneally after an overnight fast. Glucose and insulin were measured 143 at baseline and at 15, 60, and $120 \mathrm{~min}$. The intraperitoneal insulin tolerance test (IPITT) was performed 144 on day 1 of week 3 and week 11 by injecting insulin ( 1 unit $/ \mathrm{kg})$ intraperitoneally after a 6-hour fast. 145 Glucose was measured at baseline, and at 30, 60, and $120 \mathrm{~min}$.

\section{Tissue Stainings}

147 Adipocyte area was measured on pgWAT paraffin sections $(4 \mu \mathrm{m})$ stained with H\&E. pgWAT 148 macrophages were detected by F4/80 immunostaining (1:100 dilution, applied overnight; Abcam 149 \#Ab111101) and reported as positive nuclei/100 nuclei. Pancreatic beta cell density and mass were 150 estimated as previously described (15) on paraffin sections $(4 \mu \mathrm{m})$ by insulin immunostaining $(1: 100$ 151 applied overnight; DAKO \#A0564). Liver steatosis was evaluated on frozen sections (5 $\mu \mathrm{m})$ stained 152 with Oil-Red-O, where fat was quantified as \% of positive (red) staining/tissue area. The same method 153 was used for skeletal muscle fat content. For liver fibrosis, paraffin sections ( $4 \mu \mathrm{m})$ were stained with 
154 Picrosirius Red, and fibrosis was quantified as \% of positive (red) staining/tissue area (15). Liver 155 macrophages were detected on frozen sections $(5 \mu \mathrm{m})$ by CD68 immunostaining (1:50 applied 156 overnight; Serotec \#MCA1957S), and they were reported as positive nuclei/frame. Liver PGC-1 $\alpha$ 157 expression was measured on paraffin sections $(4 \mu \mathrm{m})$ by PGC-1 $\alpha$ immunostaining (1:50 applied 158 overnight; Abcam \#ab191838) and was reported as the \% of positive (brown) staining/tissue area. All 159 the sections were examined by light microscopy (Carl Zeiss - Jenaval) and digitized using a high160 resolution camera (Q-Imaging Fast 1394). The \% of staining/tissue area was quantified using Image161 ProPlus 6.3 (Media Cybernetics, Bethesda, MD, USA). Quantifications were performed on 40-100 162 frames per group.

\section{Liver triglyceride content}

For liver triglycerides (TG), $100 \mathrm{mg}$ of liver were homogenized in $1 \mathrm{ml}$ of 5\% NP40. Samples were heated at $95^{\circ}$ for 5 minutes, cooled down at RT for 5 minutes twice, and then centrifuged to collect the supernatants. Triglycerides were measured with the AU5800 analyzer (Beckman Coulter) by enzymatic

167 colorimetric method (for details, see the Supplementary Materials and Methods).

\section{Gene expression quantification by RT-qPCR}

169 Gene expression was determined by real-time quantitative RT-qPCR. In order to isolate mRNA, tissue was homogenized and processed as previously reported (16). Then, mRNA was treated to eliminate 171 DNA contamination (Ambion DNA-free product \#AM-1906), and $3 \mu \mathrm{g}$ of treated mRNA were 172 subsequently used to synthesize cDNA with Superscript First Strand synthesis system for RT-PCR 173 (Gibco BRL). The gene expression of Fas, Srebp1a, Srebp1c, Acox, Cpt1a, Ppara, Irs2, Pepck, Ppar, 174 Hnf4, Citrate synthase, Pgc-1a, Ucp2, Sirt, Pln, Gp91phox, Il-6, Tnfa, and Atg7 was analyzed by RTqPCR using the SYBR Green system (Life Technologies). Mcp1 was analyzed using the Taqman 
176 system (Life Technologies). Fluorescence for each cycle was quantitatively analyzed by StepOnePlus 177 real-time PCR system (Applied Biosystems). Gene expression was normalized to Rps9 or 18s. Results 178 are reported as ratio compared with the level of expression in untreated controls, which were given an 179 arbitrary value of 1 . Primers are reported in Supplementary Table 1.

\section{In vitro studies on HepG2 cells and mouse primary hepatocytes}

Human hepatocellular carcinoma cells (HepG2) obtained from ATCC were cultured in high glucose DMEM, supplemented with $10 \%(\mathrm{v} / \mathrm{v})$ fetal bovine serum, L-glutamine $(2 \mathrm{mM})$, penicillin $(100 \mathrm{U} / \mathrm{mL})$, and streptomycin $(100 \mu \mathrm{g} / \mathrm{mL})$ in a $5 \% \mathrm{CO}_{2}$ atmosphere at $37^{\circ} \mathrm{C}$. In order to mimic a high-fat diet milieu, cells were grown in media supplemented with either BSA-conjugated palmitate $(250 \mathrm{mM})$ or BSA-conjugated oleate $(250 \mathrm{mM})$. Cells were cultured for 24 hours with BSA-conjugated oleate with or without TRAIL (1 ng/mL) for cell viability, lipid accumulation, and protein expression studies, while they were cultured for 6 hours for gene expression analysis. Cell viability was assessed with the MTT assay (Alfa Aesar; \#L11939). Total intracellular lipid content was evaluated by Oil-Red-O staining. Protein expression of PGC-1 $\alpha$ was analyzed by immunofluorescence. Gene expression of PPAR $\gamma, P G C-1 \alpha$, and ATG7 was analyzed by RT-qPCR using the SYBR Green system (Life Technologies). cDNA was synthesized as detailed for our in vivo analyses. Fluorescence for each cycle was quantitatively analyzed by StepOnePlus real-time PCR system (Applied Biosystems). Gene expression was normalized to GADPH or Rp127, and reported as a ratio compared to the level of expression in untreated controls, which were given an arbitrary value of 1 . Primers are reported in

\section{Supplementary Table 1.}

In addition, in parallel in vitro studies, mouse primary hepatocytes were isolated from $\mathrm{C} 57 \mathrm{BL} / 6 \mathrm{~J}$ male mice following a protocol adapted from Severgnini (17). After digestion with collagenase IV, liver suspension was passed through a cell strainer. Primary hepatocytes were washed 4 times and seeded on 
199 pre-coated plates with a plating medium (Williams E Medium supplemented with CM3000, 200 ThermoFisher Scientific) for 5 hours in a $5 \% \mathrm{CO}_{2}$ atmosphere at $37^{\circ} \mathrm{C}$. Then, this medium was 201 changed to a maintenance solution (CM4000 ThermoFisher Scientific) for 24 hours before starting the 202 treatment. As before, primary hepatocytes were cultured for 24 hours with BSA-conjugated oleate $203(250 \mathrm{mM})$ or BSA alone, with or without TRAIL $(1 \mathrm{ng} / \mathrm{mL})$. Total intracellular lipid content was 204 evaluated by Oil-Red-O staining.

206 Statistics

207 Results are expressed as means \pm standard error of the mean (SEM). Differences in the mean among 208 groups were analyzed using one-way or two-way ANOVA. Pairwise multiple comparisons were made 209 using Bonferroni post-hoc analysis. A threshold of $\mathrm{p}<0.05$ was considered statistically significant. 


\section{Animal model and in vivo bioavailability of TRAIL}

212 Mice were put on a high-fat dietary regime to induce obesity and associated metabolic comorbidities 213 (Figure 1A). After 4 weeks, before drug randomization, HFD mice had increased in weight $(6.3 \pm 0.6$ 214 g) as compared to CNT mice ( $3.7 \pm 0.6 \mathrm{~g} ; \mathrm{p}<0.05$ vs HFD). HFD mice weighed $30.4 \pm 0.5 \mathrm{~g}$ and CNT 215 mice weighed $28.9 \pm 0.7 \mathrm{~g}$. There were no differences between the groups in terms of fasting glucose 216 and insulin. Nevertheless, the glucose and insulin tolerance tests showed that HFD mice had developed 217 impaired glucose tolerance as compared to CNT mice (Figure 1B). At this stage, HFD mice were 218 randomized to receive either TRAIL or saline by weekly IP injection for 8 weeks. This schedule was 219 chosen based on our previous study (7). Mice tolerated this treatment well, and they did not show any 220 sign of distress during the study or gross abnormalities at necroscopic examination as compared to 221 those treated with saline, in line with previous reports (18). When we then looked at TRAIL 222 bioavailability, we found that TRAIL was detectable after 6 hours from the IP injection and then 223 disappeared 24 hours later. This data was in line with our imaging experiment showing that the highest 224 fluorescence signal of Cy5.5-TRAIL was detected 6 hours after the IP injection, and then tended to 225 decrease over time (Figure 1C-D).

\section{TRAIL treatment significantly reduced obesity, as well as adipose and systemic inflammation}

227 At the end of the study, HFD mice became obese as compared to CNT mice. TRAIL treatment 228 significantly reduced body weight gain in HFD mice (Figure 2A), without affecting their food and 229 energy intake. In particular, HFD mice ate $2.7 \pm 0.2 \mathrm{~g} /$ day with an energy intake of $13.7 \pm 1.2$ $230 \mathrm{Kcal} /$ day, as compared to HFD+TRAIL mice, who ate $2.6 \pm 0.3 \mathrm{~g} /$ day with an energy intake of $13.4 \pm$ $2311.3 \mathrm{Kcal} /$ day. Secondly, HFD mice exhibited WAT hypertrophy, as assessed by pgWAT weight 
(Figure 2B), which is considered one of the largest visceral WAT depots (19). This was associated with an increase in the adipocyte area (Figure 2C-E) and the number of infiltrating macrophages (Figure 2E-F). TRAIL treatment significantly reduced WAT hypertrophy, adipocyte area, and macrophage accumulation in the WAT (Figure 2B-F). Thirdly, HFD mice exhibited higher levels of NEFA and CRP (Figure 2G-I), in line with the concept that excess fat is associated with high levels of NEFA (20) and a low-grade systemic inflammatory state (21). TRAIL treatment significantly reduced both NEFA and CRP (Figure 2G-I). Interestingly, TRAIL treatment was associated with a significant increase in total cholesterol, driven by an increase in HDL cholesterol.

\section{TRAIL treatment significantly reduced impaired glucose tolerance.}

The tolerance tests (Figure 3A-F) performed at the end of the study showed that the HFD resulted in impairment of glucose clearance, leading to significant hyperglycemia and hyperinsulinemia 2 hours after a glucose load (Figure 3D-E). This was associated with the inability of insulin to lower glucose levels to the levels of CNT mice (Figure 3F). At fasting, glucose did not differ between the groups, and HFD mice displayed only a significant hyperinsulinemia as compared to CNT mice (Figure 3G), indicating the presence of an insulin resistance with impaired glucose tolerance. This data was consistent with the lack of significant changes in $\beta$-cell mass and density (Figure 3H; Supplementary Figure 1). TRAIL treatment significantly reduced both impaired glucose tolerance and insulin resistance (Figure 3A-G).

\section{TRAIL treatment significantly reduced NAFLD}

To understand why TRAIL reduced impaired glucose tolerance, we looked at the tissues regulating glucose metabolism, focusing on the liver and skeletal muscle (22). At the end of the study, the HFD regime did not increase the deposition of fat (lipid droplets) in the skeletal muscle, as assessed by Oil- 
Red-O staining (data not shown). By contrast, when we looked at the liver, HFD mice developed significant steatosis (lipid accumulation $>10 \%$ of tissue area), which was assessed by Oil-Red-O staining and by TG content quantification (Figure 4 A-C). The accumulation of more than 5-10\% of fat in the liver, without any primary cause such as viral hepatitis, alcoholic disease, or drug-induced liver injury is what defines histologically non-alcoholic fatty liver disease (NAFLD) (23). In our study, HFD mice also exhibited a significant increase in liver macrophage infiltration (Figure 4C-D), but no fibrosis, which should appear after about 50 weeks of HFD (12). TRAIL treatment significantly reduced liver steatosis as well as inflammation, therefore ameliorating HFD-induced NAFLD.

\section{TRAIL significantly increased PGC-1 $\alpha$ expression in the liver}

In parallel studies, we quantitated liver mRNA encoding transcription factors and metabolic enzymes involved in de novo lipogenesis, fatty acid oxidation, glucose metabolism, and mitochondrial function, as well as pro-oxidative and proinflammatory molecules. In the liver, HFD significantly increased the

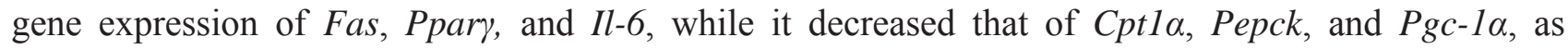
compared to CNT mice (Table 1). In HFD mice, TRAIL significantly decreased the gene expression of Fas and Il-6, while it increased that of Ppary and Pgc-1 $\alpha$ (Table 1; Figure 4E-F). The increase in Ppary and Pgc-1 $\alpha$ gene expression that followed TRAIL treatment was observed only in the liver (Supplementary Figure 2A). Given that PGC-1 $\alpha$ regulates energy metabolism and could explain part of our findings, we further evaluated it by immunostaining. In HFD mice, PGC-1 $\alpha$ protein expression increased and changed pattern of distribution as compared to CNT mice, where it was located in the nuclei. TRAIL further increased PGC-1 $\alpha$ protein expression in the liver (Figure 4C and Figure 4G). In addition, we quantitated liver mRNA encoding for Atg7, which is a protein essential for autophagy, a process that has been recently implicated in lipid metabolism regulation (24). Interestingly, an increase in Atg7 was observed in the liver of HFD+TRAIL mice (Table 1; Supplementary Figure 2A) 
277 TRAIL significantly reduced lipid droplet accumulation in hepatocytes cultured in a high-fat diet 278 milieu

279 To determine whether TRAIL had direct effects on hepatocytes, we used an in vitro model of NAFLD 280 (9), and cultured HepG2 cells with either palmitate or oleate. It must be noted that, although HepG2 281 cells are derived from liver hepatocellular carcinoma and they express TRAIL receptors 282 (Supplementary Figure 2B), they are normally resistant to TRAIL-induced apoptosis (25). MTT assay 283 showed that palmitate significantly impaired HepG2 cell viability, while oleic acid had no effect on it 284 (Figure 5A). In HepG2 cells cultured with oleic acid, TRAIL treatment promoted cell viability (Figure 285 5A), which is consistent with earlier observations that TRAIL can also activate survival pathways (26). 286 Most importantly, in these cells, TRAIL treatment reduced lipid droplet accumulation by $45 \%$ (Figure 287 5B-C). This effect was confirmed in primary hepatocytes, where TRAIL treatment reduced lipid 288 droplet accumulation by $39 \%$ (Figure 5B-C). In addition, in HepG2 cells cultured with oleic acid, 289 TRAIL upregulated PPAR $\gamma, P G C-1 \alpha$, and ATG7 gene expression (Figure 6A-C), as well as PGC-1 $\alpha$ 290 protein expression (Figure 6D), while it had no effect on specific proinflammatory markers 291 (Supplementary Figure 2C). 
294 The first new finding of this study is that TRAIL significantly ameliorated diet-induced metabolic 295 abnormalities even when it was administered after the development of impaired glucose tolerance. At 296 the end of the study, HFD mice became obese and insulin resistant, displaying impaired glucose 297 tolerance as well as an increase in NEFA and CRP levels. By comparison, the group of HFD+TRAIL 298 mice showed a significant reduction in body weight gain, NEFA and CRP levels, as well as a 299 significant amelioration of insulin resistance and impaired glucose tolerance.

Looking at the adipose tissue, TRAIL reduced body weight gain, which was associated with a decrease in fat weight, adipocyte size, and pgWAT macrophage infiltration. These findings are consistent with the earlier observations that TRAIL had significant effects on body weight. As a matter of fact, genetic TRAIL deficiency was found to be associated with increased body weight (8), and we reported that TRAIL treatment significantly reduced the adiposity of HFD-fed mice as assessed by EchoMRI (7). More recently, it has been shown that TRAIL has the ability to inhibit adipogenic differentiation through caspase activation (27). When interpreting our results in light of this finding, it is also by reducing fat mass that TRAIL could have ameliorated insulin resistance, impaired glucose tolerance, as well as circulating NEFA and CRP in HFD mice. Excess fat mass has been associated not only with insulin resistance (20), but also with high levels of NEFA (20) and a low-grade systemic inflammatory state (21). Moreover, experimental studies have shown that insulin sensitivity and systemic inflammation improve following adipose tissue removal (28).

In this study, HFD mice developed also hepatic steatosis and inflammation, corresponding to human non-alcoholic fatty liver disease (NAFLD). At present, NAFLD is found to be a frequent comorbid factor in the setting of type 2 diabetes $(29,30)$. It is estimated that about $70 \%$ of obese patients with diabetes have NAFLD and as many as $30-40 \%$ have non-alcoholic steatohepatitis (NASH), which is 
characterized by hepatic steatosis with inflammation and/or necrosis (30). Both NAFLD and NASH are conditions leading to hepatic cirrhosis, end-stage liver disease, and hepatocellular carcinoma (29).

318 Given that NAFLD is reaching epidemic proportions in diabetic patients $(29,30)$, it is predicted that cirrhosis related to NASH will surpass HCV-related cirrhosis as the most common indication for liver transplantation in the United States (31).

321 Therefore, the second important finding of this study is that TRAIL treatment markedly reduced NAFLD in the HFD-fed mouse, where it decreased liver fat content by $47 \%$. Given that NAFLD generally promotes metabolic abnormalities $(29,30)$, it is also by reducing liver fat content that TRAIL might have ameliorated insulin resistance and subclinical inflammation in HFD-fed mice. To date, only a few studies have addressed the relationship between TRAIL and NAFLD $(9,32)$. By comparison, this is the first study describing the direct effect of TRAIL in an experimental model of NAFLD. Nevertheless, our data is consistent with the finding that TRAIL deficiency worsens NAFLD (9).

There seem to be several mechanisms underlying TRAIL actions on the liver. First, the reduction in body weight gain, fat mass, and circulating NEFA, which were induced by TRAIL, could have visceral obesity (34) or adipose tissue insulin resistance/inflammation $(34,35)$. Second, the significant reduction of insulin, which was observed in the HFD+TRAIL group, could have also contributed to NAFLD amelioration. Hyperinsulinemia usually contributes to liver steatosis. Insulin promotes the synthesis and inhibits the degradation of lipids (36). It stimulates key lipogenic genes in the liver, such as fatty acid synthase (FAS), while reducing CPT1, which is the transporter of NEFA into mitochondria, thereby reducing fatty acid oxidation (36). FAS inhibitors have proven useful to reduce liver triglyceride content (37). In this study, HFD mice displayed an upregulation of Fas and a 
downregulation of Cpt1a in the liver. TRAIL significantly reduced HFD-induced Fas upregulation, consistent with the reduction of insulin and liver steatosis. Third, this study clearly shows that TRAIL also has direct actions on hepatocytes, where it significantly decreased fat content.

In this study, TRAIL significantly reduced lipid droplet accumulation in both HepG2 cells and primary hepatocytes cultured with oleate. Our results are consistent with the observation that TRAIL treatment reduces palmitate-induced lipid uptake by $30 \%$ in hepatocytes (9). Interestingly, in this study, TRAIL promoted hepatocyte cell viability and did not have anti-inflammatory effects in vitro, suggesting that the in vivo reduction of liver inflammation might be secondary to the amelioration of steatosis. In addition, TRAIL showed a direct stimulatory effect on liver Ppary and PGC-1 $\alpha$ expression in vivo, which was confirmed in vitro, where TRAIL significantly increased $P P A R \gamma$ and PGC-1 $\alpha$ expression in HepG2 cells. PPAR $\gamma$ is a nuclear receptor expressed in adipose tissue, muscle, and liver. Several studies have shown that PPAR $\gamma$ agonists significantly reduce hepatic triglyceride content and NAFLD in patients with diabetes $(38,39)$. There is a functional interaction between PPAR $\gamma$ and PGC-1 $\alpha$, which might explain the parallel increase of their gene expression induced by TRAIL (40, 41). PGC-1 $\alpha$, which is a transcriptional coactivator of nuclear receptors, is currently considered as a key component of regulatory networks that control cellular actions to adapt to higher cellular demands, such as mitochondrial function, gluconeogenesis and glucose transport, glycogenolysis, and fatty acid oxidation (42). Interestingly, PGC-1 $\alpha$ polymorphisms have been associated with obesity and increased risk of diabetes $(43,44)$. Moreover, both PGC-1 $\alpha$ (45) and PGC-1 $\alpha$-responsive genes are coordinately downregulated in human diabetes (46). When looking at the liver, it has been shown that PGC-1 $\alpha$ deficient mice (47) and liver-specific PGC-1 $\alpha$ heterozygous mice (48) develop hepatic steatosis. Moreover, PGC-1 $\alpha$ seems to have a suppressive effect on liver inflammation (49). Therefore, our results suggest that TRAIL effects on the liver and glucose metabolism might involve PPAR $\gamma$ and/or PGC- $1 \alpha$ actions. 
363 In addition, based on our in vitro studies, where TRAIL increased ATG7, a possible unifying 364 hypothesis explaining TRAIL effects on liver steatosis and PGC-1 $\alpha$ is that they might be due to 365 TRAIL-induced liver autophagy (50). Autophagy is a mechanism by which TG content, lipid droplet 366 number and size is regulated. In this process, lipids are sequestered in autophagosomes where they are 367 degraded (24). This should stimulate mitochondrial $\beta$-oxidation (24). Moreover, autophagy seems to 368 regulate the flux of cholesterol out of the cell to APOA-I (51), which is the major component of HDL 369 and could explain the increase in HDL cholesterol that we found in HFD+TRAIL mice. Further studies 370 are needed to evaluate the mechanisms underlying TRAIL effect on liver steatosis and PGC-1 $\alpha$, as well 371 as to test in detail the hypothesis that they might include TRAIL actions on liver autophagy.

372 In conclusion, this study shows that TRAIL was effective in reducing HFD-induced metabolic 373 abnormalities even when it was administered after the development of impaired glucose tolerance. 374 Second, this study shows that TRAIL markedly improved NAFLD in HFD-fed mice, and that this was 375 associated with a significant increase in PGC-1 $\alpha$. Overall, our results shed light on the therapeutic 376 potential of TRAIL against diabetes, NAFLD, and NASH. 
- Experimental evidence suggests that a circulating protein called TRAIL protects against type 2 diabetes. This study was designed to evaluate whether TRAIL had the potential not only to prevent, but also to treat diet-induced type 2 diabetes.

- Our in vivo results show that TRAIL had the ability to attenuate the metabolic abnormalities induced by a high-fat diet, also when TRAIL was given after disease onset (after 4 weeks of high-fat diet). In particular, TRAIL treatment significantly reduced body weight, impaired glucose tolerance, and liver steatosis, all of which are frequently associated with type 2 diabetes.

- Our in vitro results show that TRAIL has direct effects on hepatocytes, where it reduces lipid droplet accumulation. This data sheds light on TRAIL therapeutic potential against impaired glucose tolerance and NAFLD. 
392 We acknowledge Dr. Barbara Dapas (Department of Life Sciences Università degli Studi di Trieste.

393 Italy) for her technical support in in vitro experiments, as well as the Foundation "Dott. Carlo

394 Fornasini” (Poggio Renatico, Ferrara, Italy).

395 Declarations of interest

396 All Authors have no conflicts of interest.

$397 \quad$ Funding

398 This work was supported by research funding from Italian Ministry of Health to Stella Bernardi (GR399 2013-02357830), and to V.T. (GR-2010-2310832), and from Università degli Studi di Trieste to B.F 400 (FRA-2012).

\section{Author contribution}

402 S. Bernardi conception and design, acquisition, analysis and interpretation of data, and drafting the 403 article; B.T. acquisition, analysis and interpretation of data and drafting article; V.T. F.B. S. Biffi and 404 A.L. acquisition, analysis and interpretation of data; G.Z. P.S. conception, interpretation of data and 405 article revision for important intellectual content; B.F. conception and design, and article revision for 406 important intellectual content. All the authors have read and approved the submission of this 407 manuscript. 


\section{References}

1. Ashkenazi A, Herbst RS. To kill a tumor cell: the potential of proapoptotic receptor agonists. J Clin Invest. 2008;118(6):1979-90.

2. Harith HH, Morris MJ, Kavurma MM. On the TRAIL of obesity and diabetes. Trends Endocrinol Metab. 2013;24(11):578-87.

3. Bossi F, Bernardi S, Zauli G, Secchiero P, Fabris B. TRAIL modulates the immune system and protects against the development of diabetes. J Immunol Res. 2015;2015:680749.

4. Mi QS, Ly D, Lamhamedi-Cherradi SE, Salojin KV, Zhou L, Grattan M, et al. Blockade of tumor necrosis factor-related apoptosis-inducing ligand exacerbates type 1 diabetes in NOD mice. Diabetes. 2003;52(8):196775.

5. Lamhamedi-Cherradi SE, Zheng S, Tisch RM, Chen YH. Critical roles of tumor necrosis factor-related apoptosis-inducing ligand in type 1 diabetes. Diabetes. 2003;52(9):2274-8.

6. Zauli G, Toffoli B, di lasio MG, Celeghini C, Fabris B, Secchiero P. Treatment with recombinant tumor necrosis factor-related apoptosis-inducing ligand alleviates the severity of streptozotocin-induced diabetes. Diabetes. 2010;59(5):1261-5.

7. Bernardi S, Zauli G, Tikellis C, Candido R, Fabris B, Secchiero P, et al. TNF-related apoptosis-inducing ligand significantly attenuates metabolic abnormalities in high-fat-fed mice reducing adiposity and systemic inflammation. Clin Sci (Lond). 2012;123(9):547-55.

8. Di Bartolo BA, Chan J, Bennett MR, Cartland S, Bao S, Tuch BE, et al. TNF-related apoptosis-inducing ligand (TRAIL) protects against diabetes and atherosclerosis in Apoe $(-) /(-)$ mice. Diabetologia. 2011;54(12):3157-67.

9. Cartland SP, Harith HH, Genner SW, Dang L, Cogger VC, Vellozzi M, et al. Non-alcoholic fatty liver disease, vascular inflammation and insulin resistance are exacerbated by TRAIL deletion in mice. Sci Rep. 2017;7(1):1898.

10. Winzell MS, Ahren B. The high-fat diet-fed mouse: a model for studying mechanisms and treatment of impaired glucose tolerance and type 2 diabetes. Diabetes. 2004;53 Suppl 3:S215-9.

11. King AJ. The use of animal models in diabetes research. Br J Pharmacol. 2012;166(3):877-94.

12. Ito M, Suzuki J, Tsujioka S, Sasaki M, Gomori A, Shirakura T, et al. Longitudinal analysis of murine steatohepatitis model induced by chronic exposure to high-fat diet. Hepatol Res. 2007;37(1):50-7.

13. MacFarlane M, Ahmad M, Srinivasula SM, Fernandes-Alnemri T, Cohen GM, Alnemri ES. Identification and molecular cloning of two novel receptors for the cytotoxic ligand TRAIL. J Biol Chem. 1997;272(41):2541720.

14. Tisato V, Garrovo C, Biffi S, Petrera F, Voltan R, Casciano F, et al. Intranasal administration of recombinant TRAIL down-regulates $\mathrm{CXCL}-1 / K C$ in an ovalbumin-induced airway inflammation murine model. PLoS One. 2014;9(12):e115387.

15. Toffoli B, Bernardi S, Candido R, Sabato N, Carretta R, Corallini F, et al. Osteoprotegerin induces morphological and functional alterations in mouse pancreatic islets. Mol Cell Endocrinol. 2011;331(1):136-42.

16. Bernardi S, Tikellis C, Candido R, Tsorotes D, Pickering RJ, Bossi F, et al. ACE2 deficiency shifts energy metabolism towards glucose utilization. Metabolism. 2015;64(3):406-15.

17. Severgnini M, Sherman J, Sehgal A, Jayaprakash NK, Aubin J, Wang G, et al. A rapid two-step method for isolation of functional primary mouse hepatocytes: cell characterization and asialoglycoprotein receptor based assay development. Cytotechnology. 2012;64(2):187-95.

18. Secchiero P, Candido R, Corallini F, Zacchigna S, Toffoli B, Rimondi E, et al. Systemic tumor necrosis factor-related apoptosis-inducing ligand delivery shows antiatherosclerotic activity in apolipoprotein E-null diabetic mice. Circulation. 2006;114(14):1522-30. 
19. Sanchez-Gurmaches J, Hung CM, Guertin DA. Emerging Complexities in Adipocyte Origins and Identity. Trends Cell Biol. 2016;26(5):313-26.

20. Heymsfield SB, Wadden TA. Mechanisms, Pathophysiology, and Management of Obesity. N Engl J Med. 2017;376(3):254-66.

21. Visser M, Bouter LM, McQuillan GM, Wener MH, Harris TB. Elevated C-reactive protein levels in overweight and obese adults. JAMA. 1999;282(22):2131-5.

22. Defronzo RA. Banting Lecture. From the triumvirate to the ominous octet: a new paradigm for the treatment of type 2 diabetes mellitus. Diabetes. 2009;58(4):773-95.

23. Haga Y, Kanda T, Sasaki R, Nakamura M, Nakamoto S, Yokosuka O. Nonalcoholic fatty liver disease and hepatic cirrhosis: Comparison with viral hepatitis-associated steatosis. World J Gastroenterol. 2015;21(46):12989-95.

24. Liu K, Czaja MJ. Regulation of lipid stores and metabolism by lipophagy. Cell Death Differ. 2013;20(1):311.

25. Sun J, Yu X, Wang C, Yu C, Li Z, Nie W, et al. RIP-1/c-FLIPL Induce Hepatic Cancer Cell Apoptosis Through Regulating Tumor Necrosis Factor-Related Apoptosis-Inducing Ligand (TRAIL). Med Sci Monit. 2017;23:1190-9.

26. Toffoli B, Bernardi S, Candido R, Zacchigna S, Fabris B, Secchiero P. TRAIL shows potential cardioprotective activity. Invest New Drugs. 2012;30(3):1257-60.

27. Zoller V, Funcke JB, Keuper M, Abd El Hay M, Debatin KM, Wabitsch M, et al. TRAIL (TNF-related apoptosis-inducing ligand) inhibits human adipocyte differentiation via caspase-mediated downregulation of adipogenic transcription factors. Cell Death Dis. 2016;7(10):e2412.

28. Pitombo C, Araujo EP, De Souza CT, Pareja JC, Geloneze B, Velloso LA. Amelioration of diet-induced diabetes mellitus by removal of visceral fat. J Endocrinol. 2006;191(3):699-706.

29. Tilg H, Moschen AR, Roden M. NAFLD and diabetes mellitus. Nat Rev Gastroenterol Hepatol. 2017;14(1):32-42.

30. Cusi K. Treatment of patients with type 2 diabetes and non-alcoholic fatty liver disease: current approaches and future directions. Diabetologia. 2016;59(6):1112-20.

31. Ge PS, Runyon BA. Treatment of Patients with Cirrhosis. N Engl J Med. 2016;375(8):767-77.

32. Idrissova L, Malhi H, Werneburg NW, LeBrasseur NK, Bronk SF, Fingas C, et al. TRAIL receptor deletion in mice suppresses the inflammation of nutrient excess. J Hepatol. 2015;62(5):1156-63.

33. Donnelly KL, Smith Cl, Schwarzenberg SJ, Jessurun J, Boldt MD, Parks EJ. Sources of fatty acids stored in liver and secreted via lipoproteins in patients with nonalcoholic fatty liver disease. J Clin Invest. 2005;115(5):1343-51.

34. Tchkonia T, Thomou T, Zhu Y, Karagiannides I, Pothoulakis C, Jensen MD, et al. Mechanisms and metabolic implications of regional differences among fat depots. Cell Metab. 2013;17(5):644-56.

35. Perry RJ, Camporez JP, Kursawe R, Titchenell PM, Zhang D, Perry CJ, et al. Hepatic acetyl CoA links adipose tissue inflammation to hepatic insulin resistance and type 2 diabetes. Cell. 2015;160(4):745-58.

36. Weickert MO, Pfeiffer AF. Signalling mechanisms linking hepatic glucose and lipid metabolism. Diabetologia. 2006;49(8):1732-41.

37. Wu M, Singh SB, Wang J, Chung CC, Salituro G, Karanam BV, et al. Antidiabetic and antisteatotic effects of the selective fatty acid synthase (FAS) inhibitor platensimycin in mouse models of diabetes. Proc Natl Acad Sci U S A. 2011;108(13):5378-83.

38. Mayerson AB, Hundal RS, Dufour S, Lebon V, Befroy D, Cline GW, et al. The effects of rosiglitazone on insulin sensitivity, lipolysis, and hepatic and skeletal muscle triglyceride content in patients with type 2 diabetes. Diabetes. 2002;51(3):797-802.

39. Cusi K, Orsak B, Bril F, Lomonaco R, Hecht J, Ortiz-Lopez C, et al. Long-Term Pioglitazone Treatment for Patients With Nonalcoholic Steatohepatitis and Prediabetes or Type 2 Diabetes Mellitus: A Randomized Trial. Ann Intern Med. 2016;165(5):305-15. 
502 40. Fujisawa K, Nishikawa T, Kukidome D, Imoto K, Yamashiro T, Motoshima H, et al. TZDs reduce 503 mitochondrial ROS production and enhance mitochondrial biogenesis. Biochem Biophys Res Commun. 504 2009;379(1):43-8.

505 41. Puigserver P, Wu Z, Park CW, Graves R, Wright M, Spiegelman BM. A cold-inducible coactivator of 506 nuclear receptors linked to adaptive thermogenesis. Cell. 1998;92(6):829-39.

507 42. Wu H, Deng X, Shi Y, Su Y, Wei J, Duan H. PGC-1alpha, glucose metabolism and type 2 diabetes mellitus. 508 J Endocrinol. 2016;229(3):R99-R115.

509 43. Ek J, Andersen G, Urhammer SA, Gaede PH, Drivsholm T, Borch-Johnsen K, et al. Mutation analysis of 510 peroxisome proliferator-activated receptor-gamma coactivator-1 (PGC-1) and relationships of identified amino 511 acid polymorphisms to Type II diabetes mellitus. Diabetologia. 2001;44(12):2220-6.

512 44. Hara K, Tobe K, Okada T, Kadowaki H, Akanuma Y, Ito C, et al. A genetic variation in the PGC-1 gene 513 could confer insulin resistance and susceptibility to Type II diabetes. Diabetologia. 2002;45(5):740-3.

514 45. Patti ME, Butte AJ, Crunkhorn S, Cusi K, Berria R, Kashyap S, et al. Coordinated reduction of genes of 515 oxidative metabolism in humans with insulin resistance and diabetes: Potential role of PGC1 and NRF1. Proc $516 \quad$ Natl Acad Sci U S A. 2003;100(14):8466-71.

517 46. Mootha VK, Lindgren CM, Eriksson KF, Subramanian A, Sihag S, Lehar J, et al. PGC-1alpha-responsive 518 genes involved in oxidative phosphorylation are coordinately downregulated in human diabetes. Nat Genet. $5192003 ; 34(3): 267-73$.

520 47. Leone TC, Lehman JJ, Finck BN, Schaeffer PJ, Wende AR, Boudina S, et al. PGC-1alpha deficiency causes 521 multi-system energy metabolic derangements: muscle dysfunction, abnormal weight control and hepatic 522 steatosis. PLoS Biol. 2005;3(4):e101.

523 48. Estall JL, Kahn M, Cooper MP, Fisher FM, Wu MK, Laznik D, et al. Sensitivity of lipid metabolism and 524 insulin signaling to genetic alterations in hepatic peroxisome proliferator-activated receptor-gamma 525 coactivator-1alpha expression. Diabetes. 2009;58(7):1499-508.

526 49. Barroso WA, Victorino VJ, Jeremias IC, Petroni RC, Ariga SKK, T AS, et al. High-fat diet inhibits PGC527 1alpha suppressive effect on NFkappaB signaling in hepatocytes. Eur J Nutr. 2017.

528 50. Nikoletopoulou V, Markaki M, Palikaras K, Tavernarakis N. Crosstalk between apoptosis, necrosis and 529 autophagy. Biochim Biophys Acta. 2013;1833(12):3448-59.

530 51. Ouimet M, Franklin V, Mak E, Liao X, Tabas I, Marcel YL. Autophagy regulates cholesterol efflux from 531 macrophage foam cells via lysosomal acid lipase. Cell Metab. 2011;13(6):655-67. 
Tables

535 Table 1. Liver gene expression analysis

\begin{tabular}{|c|c|c|c|c|c|c|}
\hline & CNT & HFD & HFD + TRAIL & HFD vs CNT & $\begin{array}{c}\text { HFD + TRAIL } \\
\text { vs CNT }\end{array}$ & $\begin{array}{l}\text { HFD vs HFD } \\
\text { + TRAIL }\end{array}$ \\
\hline \multicolumn{7}{|c|}{ De novo lipogenesis } \\
\hline Fas & $1.00 \pm 0.10$ & $1.60 \pm 0.11$ & $1.20 \pm 0.07$ & $<0.01$ & NS & $<0.05$ \\
\hline Srebp1a & $1.00 \pm 0.04$ & $1.17 \pm 0.10$ & $1.16 \pm 0.11$ & NS & NS & NS \\
\hline Srebp1c & $1.00 \pm 0.20$ & $0.70 \pm 0.06$ & $1.17 \pm 0.21$ & NS & NS & NS \\
\hline \multicolumn{7}{|c|}{ Fatty acid oxidation } \\
\hline Aox & $1.00 \pm 0.08$ & $0.77 \pm 0.06$ & $0.83 \pm 0.07$ & NS & NS & NS \\
\hline Cpt1a & $1.00 \pm 0.06$ & $0.51 \pm 0.07$ & $0.55 \pm 0.07$ & $<0.0001$ & $<0.0001$ & NS \\
\hline Ppara & $1.00 \pm 0.11$ & $0.75 \pm 0.14$ & $0.85 \pm 0.15$ & NS & NS & NS \\
\hline \multicolumn{7}{|c|}{ Gluconeogenesis, insulin signaling, insulin sensitivity } \\
\hline Irs2 & $1.00 \pm 0.09$ & $0.79 \pm 0.08$ & $0.74 \pm 0.12$ & NS & NS & NS \\
\hline Pepck & $1.00 \pm 0.10$ & $0.30 \pm 0.09$ & $0.32 \pm 0.06$ & $<0.0001$ & $<0.0001$ & NS \\
\hline Ppary & $1.00 \pm 0.10$ & $1.82 \pm 0.21$ & $2.57 \pm 0.20$ & $<0.01$ & $<0.0001$ & $<0.05$ \\
\hline Hnf4 & $1.00 \pm 0.11$ & $0.99 \pm 0.11$ & $1.07 \pm 0.09$ & NS & NS & NS \\
\hline \multicolumn{7}{|c|}{ Mitochondrial function } \\
\hline Cit synt & $1.00 \pm 0.09$ & $1.00 \pm 0.11$ & $1.12 \pm 0.08$ & NS & NS & NS \\
\hline$P g c-1 \alpha$ & $1.00 \pm 0.05$ & $0.41 \pm 0.05$ & $0.65 \pm 0.03$ & $<0.0001$ & $<0.0001$ & $<0.01$ \\
\hline Pln5 & $1.00 \pm 0.21$ & $0.72 \pm 0.07$ & $0.81 \pm 0.08$ & NS & NS & NS \\
\hline Ucp2 & $1.00 \pm 0.11$ & $0.69 \pm 0.07$ & $0.79 \pm 0.11$ & NS & NS & NS \\
\hline Sirt-1 & $1.00 \pm 0.07$ & $1.06 \pm 0.10$ & $1.03 \pm 0.06$ & NS & NS & NS \\
\hline \multicolumn{7}{|c|}{ Oxidative stress and inflammation } \\
\hline Gp91phox & $1.00 \pm 0.13$ & $0.83 \pm 0.15$ & $0.86 \pm 0.16$ & NS & NS & NS \\
\hline $11-6$ & $1.00 \pm 0.18$ & $1.74 \pm 0.14$ & $1.16 \pm 0.10$ & $<0.01$ & NS & $<0.05$ \\
\hline Mcp1 & $1.00 \pm 0.20$ & $1.95 \pm 0.25$ & $1.99 \pm 0.38$ & NS & NS & NS \\
\hline Tnfo & $1.00 \pm 0.14$ & $0.82 \pm 0.12$ & $1.14 \pm 0.23$ & NS & NS & NS \\
\hline \multicolumn{7}{|c|}{ Autophagy } \\
\hline Atg7 & $1.00 \pm 0.06$ & $1.33 \pm 0.12$ & $1.53 \pm 0.11$ & $<0.05$ & $<0.01$ & NS \\
\hline
\end{tabular}

537 Fatty acid synthase (Fas), sterol regulatory element binding protein-1a (Srebp1a), and sterol regulatory 538 element binding protein-1c (Srebp1c) are transcription factors and enzymes involved in lipogenesis. 539 Acyl-CoA oxidase (Aox), carnitine palmitoyl transferase-1a (Cpt1a), and peroxisome proliferator540 activated receptor $($ Ppar $\alpha$ ) are transcription factors and enzymes involved in fatty acid oxidation. Irs2 541 regulates insulin signaling; Pepck regulates gluconeogenesis; peroxisome proliferator-activated 
542 receptor $\gamma($ Ppar $\gamma)$ sensitizes to insulin. Hepatocyte nuclear factor 4 (Hnf4) is a transcriptional regulator 543 of gluconeogenic genes. Citrate synthase (Cit synt), which is the pace-making enzyme of Krebs cycle, 544 and uncoupling protein2 (Ucp2) are localized in mitochondria, while PPAR $\gamma$ coactivator $1 \alpha(P g c-1 \alpha)$, 545 perilipin 5 (Pln5), and sirtuin-1 (Sirt-1) regulate mitochondrial functions. Gp91phox is a subunit of 546 NADPH oxidase, which is involved in oxidative stress, interleukin-6 (Il-6), monocyte chemoattractant 547 protein-1 (Mcp1), and Tnfo are proiflammatory mediators. Autophagy-related protein 7 (Atg7) is a 548 molecule involved in autophagy. 
Figure 1. Treatment protocol. (A) Schematic illustration of the protocol: C57BL/6J mice were fed either a standard diet (SD; $12 \%$ fat) or a high-fat diet (HFD; $60 \%$ fat) for 12 weeks. Mice on HFD were treated either with saline $(\mathrm{NaCl} 0.9 \%)$ or TRAIL weekly between week 5 and week 12 . Mice on SD were treated with saline. $(*)$ Tolerance tests before drug randomization; $(* *)$ Tolerance tests at the end of the study (B) Glucose and insulin tolerance tests performed before drug randomization. Upper figures show blood glucose and its area under the curve (AUC) during an IPGTT, middle figures show serum insulin and its AUC during an IPGTT, lower figures show blood glucose and its AUC during an IPITT (C) Representative images of Cy5.5-TRAIL clearance from the peritoneal cavity, as assessed by acquisition of fluorescence emission from the peritoneum after an IP injection of $10 \mu \mathrm{g}$ of Cy5.5TRAIL. Cy5.5-TRAIL is TRAIL that was labeled with N-hydrosuccinimmide ester of the cyanine 5.5. Fluorescence emission was collected at $700 \mathrm{~nm}$. For further details, see (14). (D) Circulating human TRAIL after IP injection of $10 \mu \mathrm{g}$ of TRAIL.

Figure 2. Body weight, adipose tissue, and inflammation. (A) Body weight throughout the study. The gray area corresponds to the treatment period. (B) Perigonadal white adipose tissue (pgWAT) weight at the end of the study. (C-D) Frequency distribution and adipocyte area. (E) Representative images of pgWAT H\&E staining (upper panel; 12.5x, scale bar $50 \mu \mathrm{m}$ ) and F4/80+ macrophages (lower panels; 25x, scale bar $50 \mu \mathrm{m}$ ). (G) NEFA levels at the end of the study. (H) Total cholesterol (TC), HDL cholesterol (HDL-C), and triglycerides (TG) at the end of the study. (I) C-reactive protein levels at the end of the study. Results are presented as mean $\pm \mathrm{SEM} ;{ }^{*} \mathrm{p}<0.05$ vs CNT; $\# \mathrm{p}<0.05$ vs HFD.

Figure 3. Glucose metabolism. (A-F) Glucose and insulin tolerance tests performed at the end of the 
during an IPITT; (D) Area under the curve (AUC) of the glucose levels during the IPGTT; (E) AUC of the insulin levles during the IPGTT; (F) AUC of the glucose levels during the IPITT; (G) Fasting 575 glucose and insulin ant the end of the study. (H) Representative images of pancreatic sections 576 immunostained for insulin $(25 \mathrm{x}$, scale bar $50 \mu \mathrm{m})$. Results are presented as mean $\pm \mathrm{SEM} ;{ }^{*} \mathrm{p}<0.05$ vs 577 CNT; \# $\mathrm{p}<0.05$ vs HFD.

578 Figure 4. Liver changes. (A) Liver triglyceride content; (B) Percentage of hepatic area positive for fat 579 (stained red) with Oli-Red-O (ORO). (C) Representative images of liver ORO staining (25x, scale bar $58050 \mu \mathrm{m})$, Picrosirius Red (Sirius Red) staining (12.5X, scale bar $100 \mu \mathrm{m})$, CD68+ macrophages (12.5X, 581 scale bar $100 \mu \mathrm{m})$, and PGC-1 $\alpha$ staining (12.5X, scale bar $100 \mu \mathrm{m})$. (D) Quantification of CD68+ cells 582 (brown nuclei)/frame liver tissue. (E) Liver mRNA expression of Il-6. Il-6 is for interleukin-6. mRNA 583 expression is reported as fold induction standardized to the mRNA expression in CNT mice. (F) Liver mRNA expression of $P g c-1 \alpha . P g c-1 \alpha$ is for peroxisome proliferator-activated receptor- $\gamma$ coactivator-1 alpha. mRNA expression is reported as fold induction standardized to the mRNA expression in CNT mice. (G) Quantification of PGC-1 $\alpha+$ staining (brown)/area of liver tissue. Results are presented as mean \pm SEM; $* \mathrm{p}<0.05$ vs CNT; \# $\mathrm{p}<0.05$ vs HFD.

Figure 5. Hepatic lipid droplet accumulation in vitro. (A) HepG2 cell viability after exposure to palmitic acid or oleic acid in presence or absence of TRAIL. (B) HepG2 and mPH percentage of cell surface positive for lipid droplets (dark red staining) with Oil-Red-O (ORO). Cells were incubated with oleic acid $(250 \mu \mathrm{M})$ in presence or absence of TRAIL $(1 \mathrm{ng} / \mathrm{mL})$. HepG2 is for HepG2 cells and mPH is for mouse primary hepatocytes. (C) Representative images of HepG2 cells (upper panel) and mouse primary hepatocytes (lower panel) stained with ORO (20x, scale bar $100 \mu \mathrm{m})$. Results are presented as mean \pm SEM; $* \mathrm{p}<0.05$ vs control; $\# \mathrm{p}<0.05$ vs oleic acid without TRAIL. 
595 Figure 6. In vitro studies on HepG2 cells. (A) HepG2 cell mRNA expression of $P P A R \gamma ;$ (B) $P G C-1 \alpha$;

596 (C) ATG7. (D) Representative images of PGC-1 $\alpha$ immunostaining on HepG2 cells. Results are 597 presented as mean $\pm \mathrm{SEM} ; * \mathrm{p}<0.05$ vs control without TRAIL. 
A

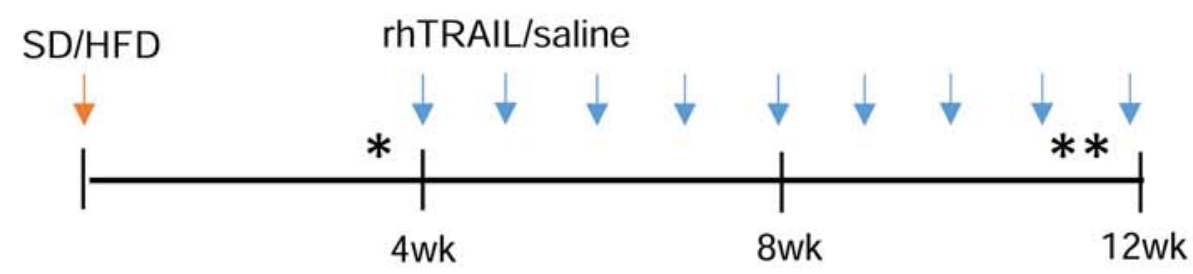

B
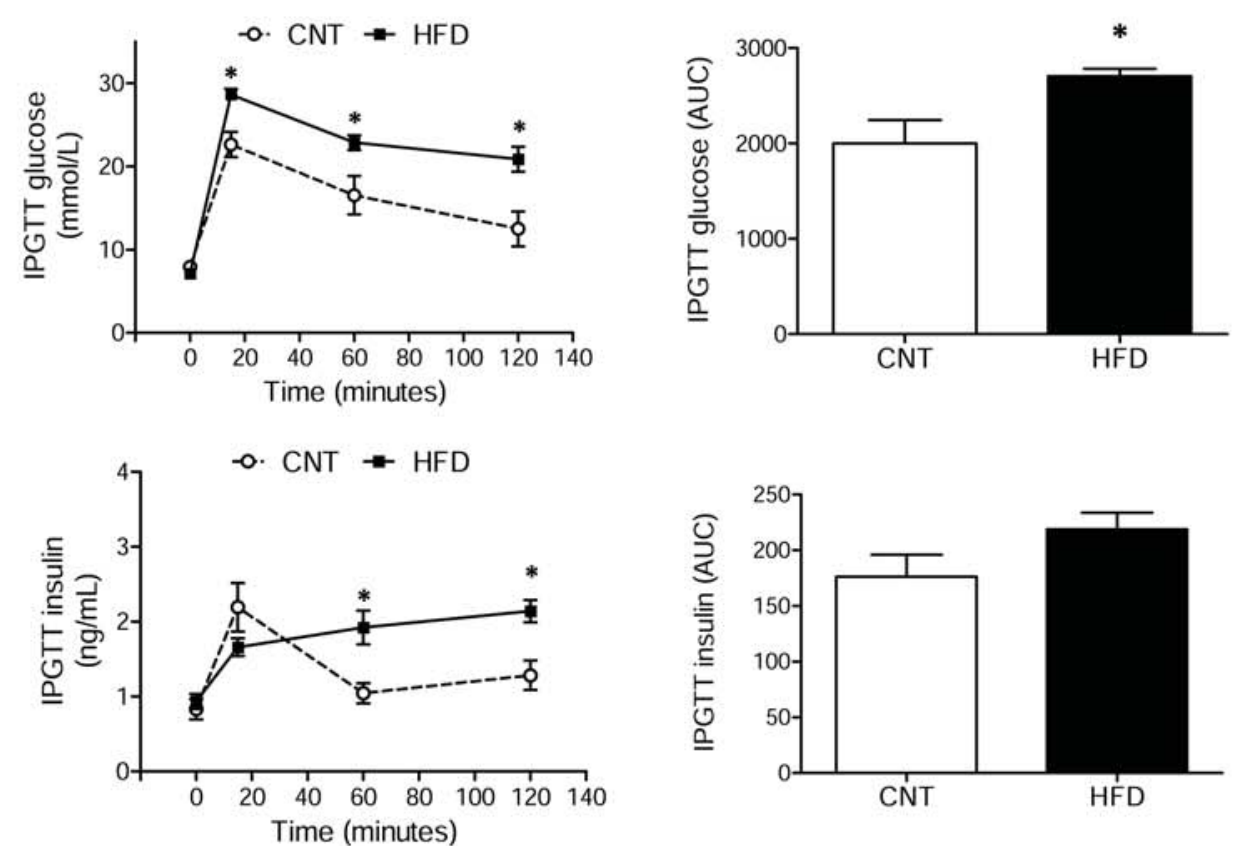

C
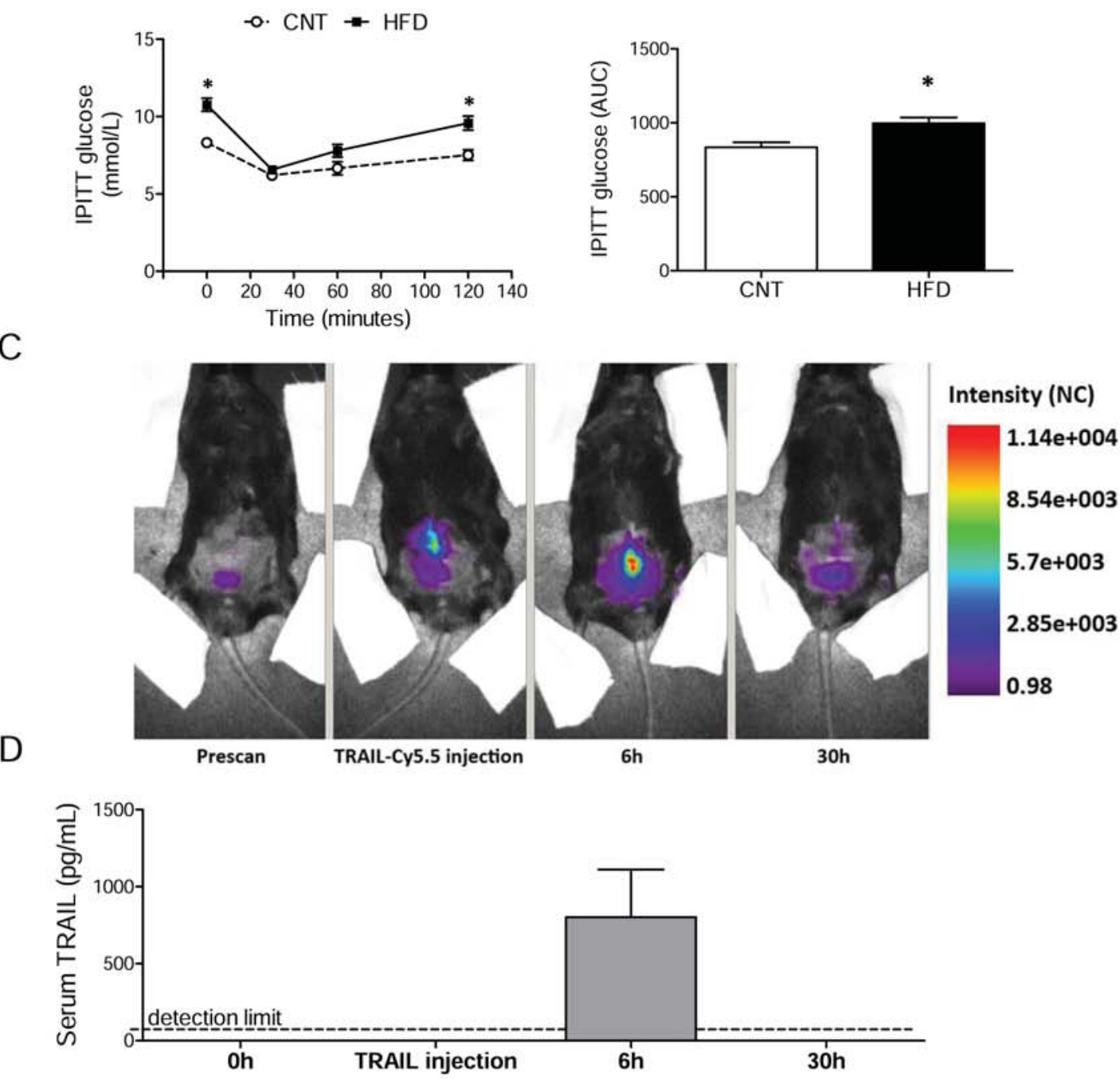

Figure 1 
Figure 2

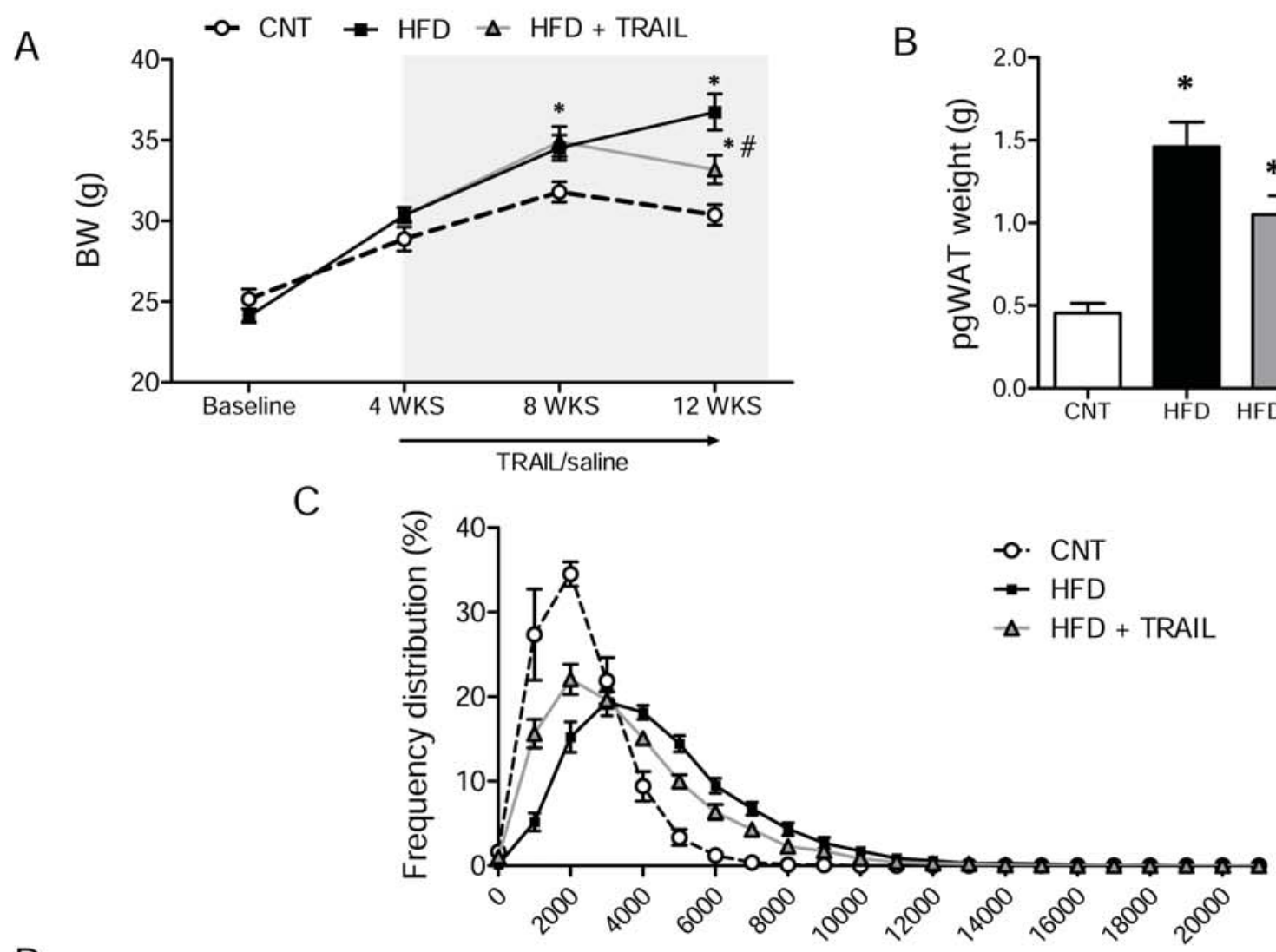

D

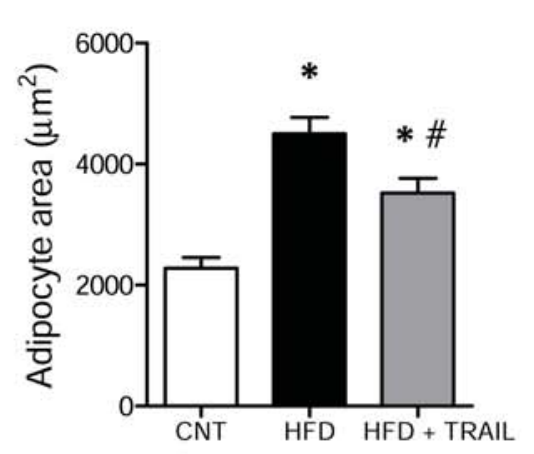

Adipocyte area $\left(\mu \mathrm{m}^{2}\right)$

F

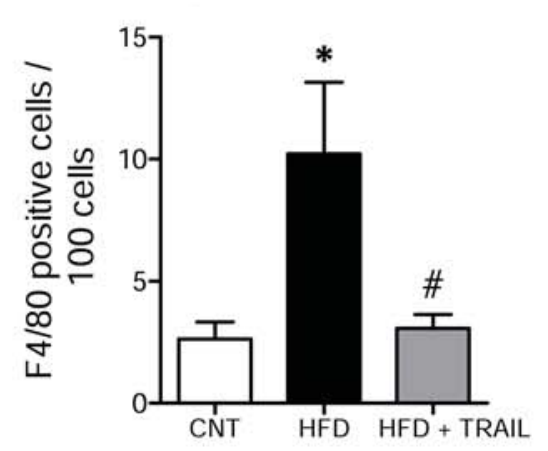

E
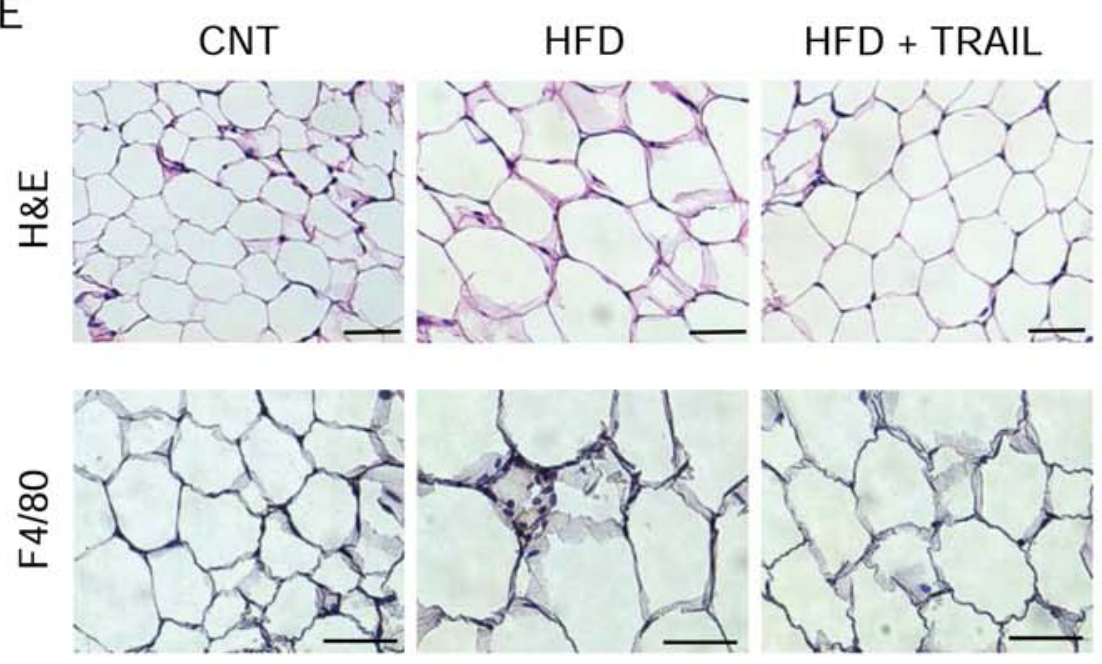

G

$\mathrm{H}$
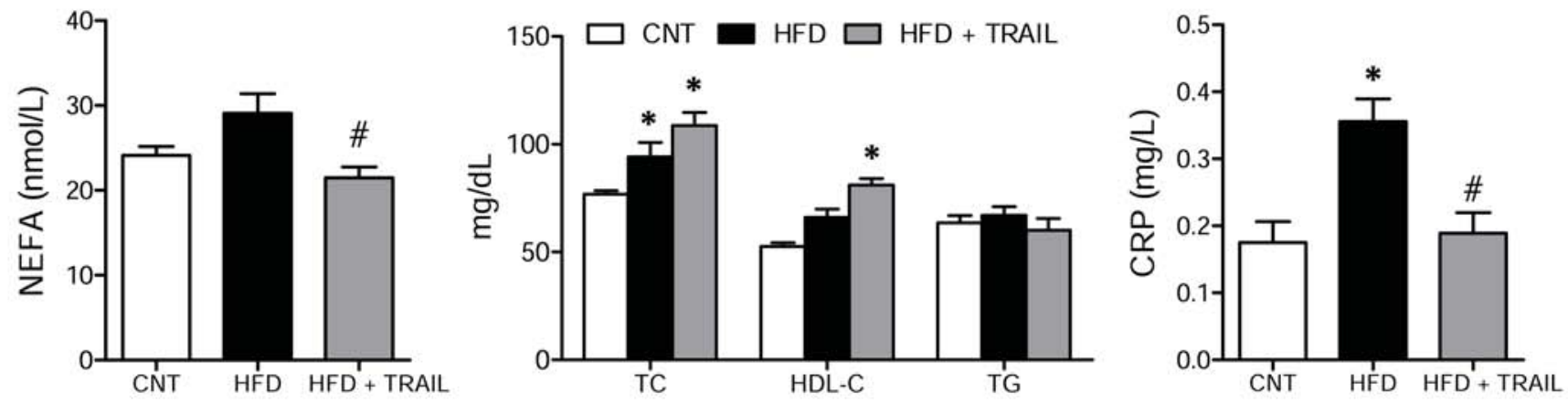
Figure 3

A
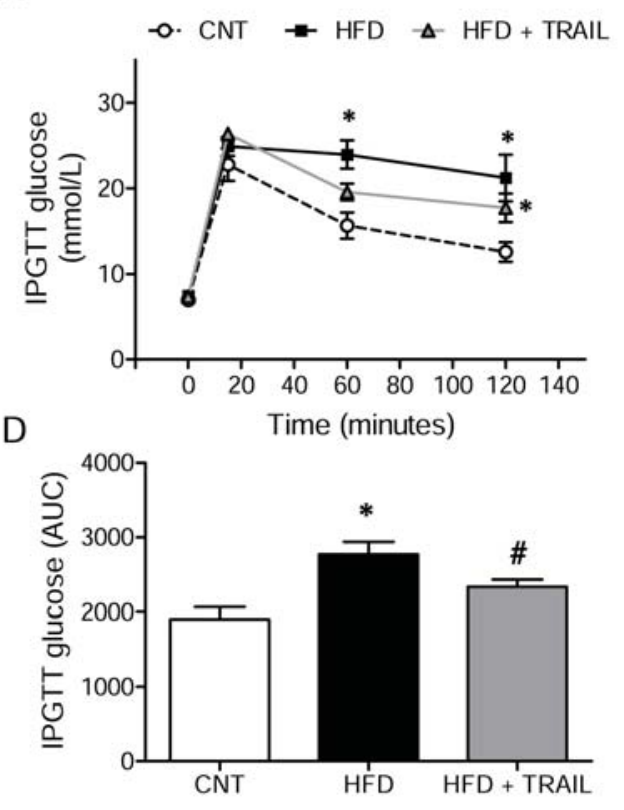

B
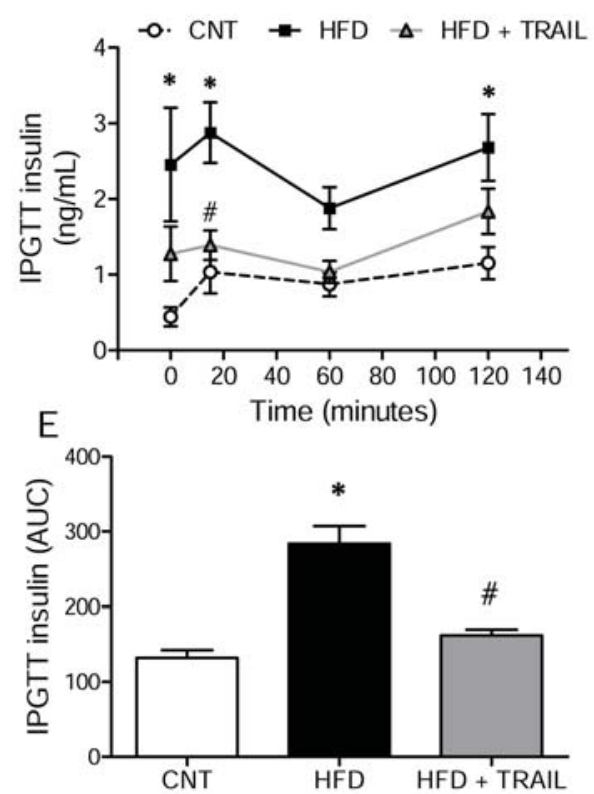

G
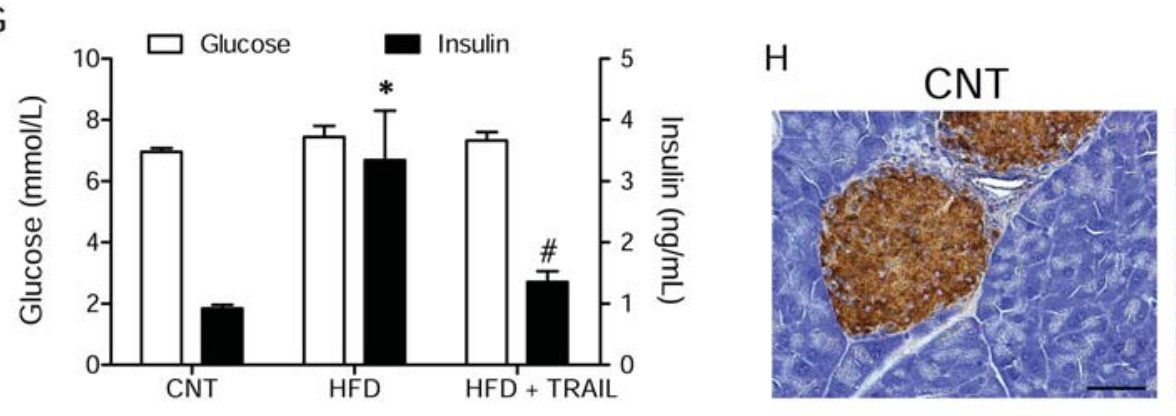

C
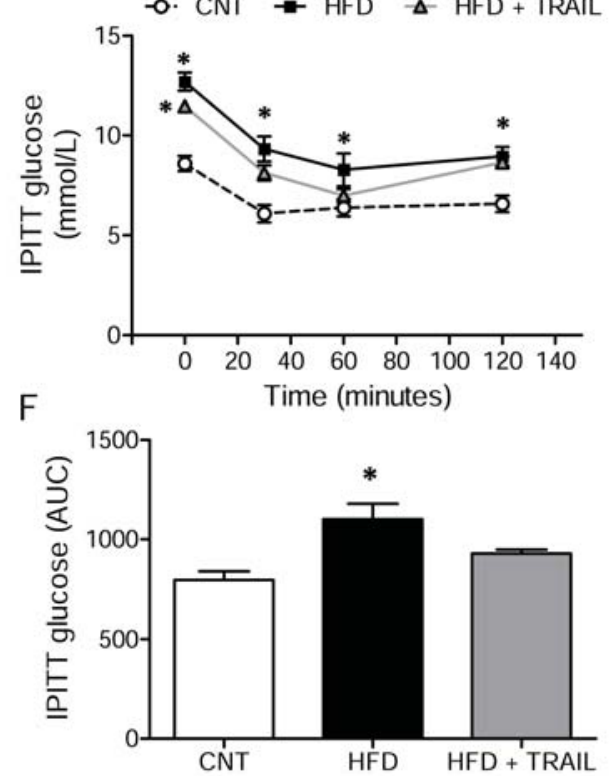
Figure 4
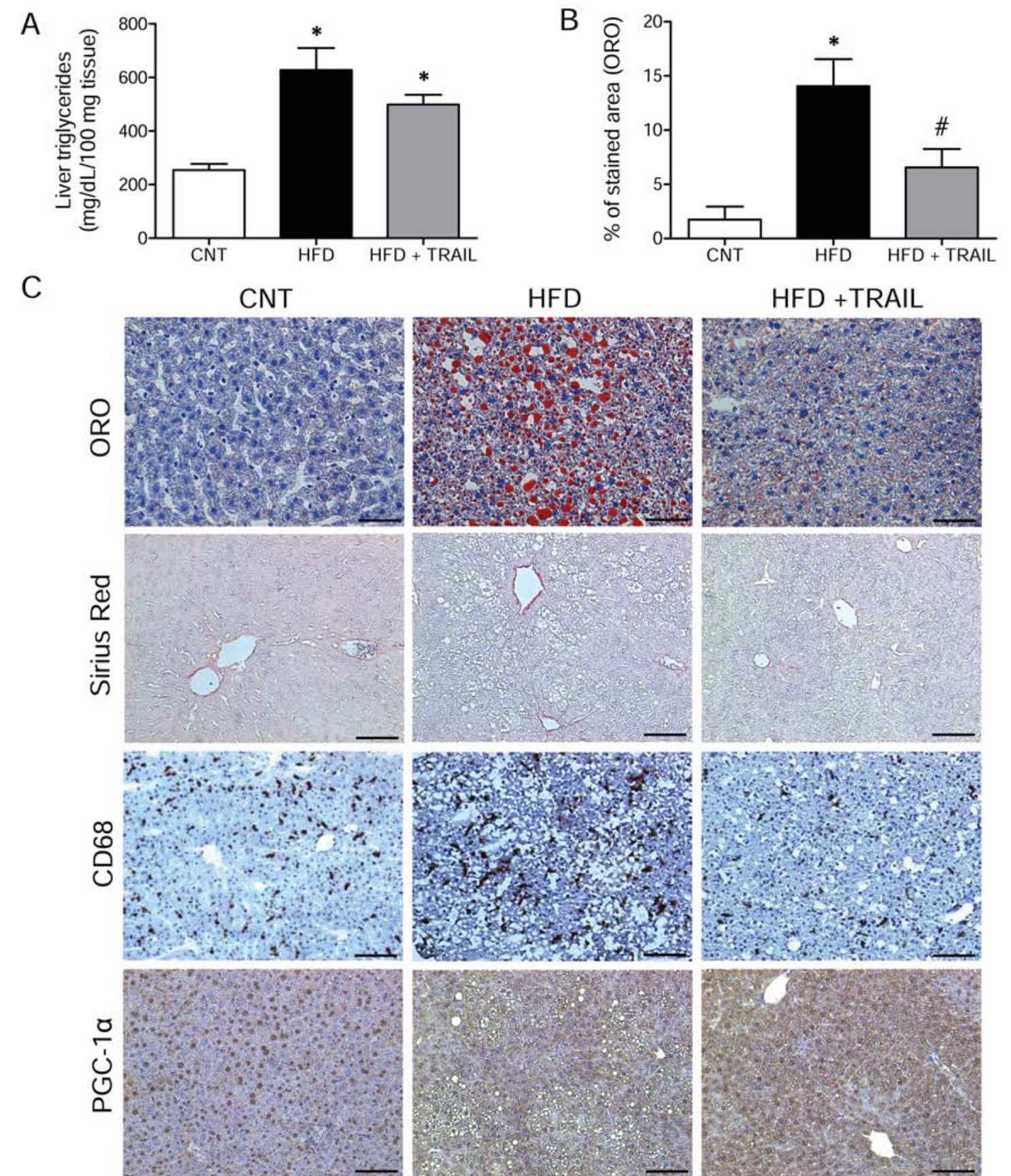

D

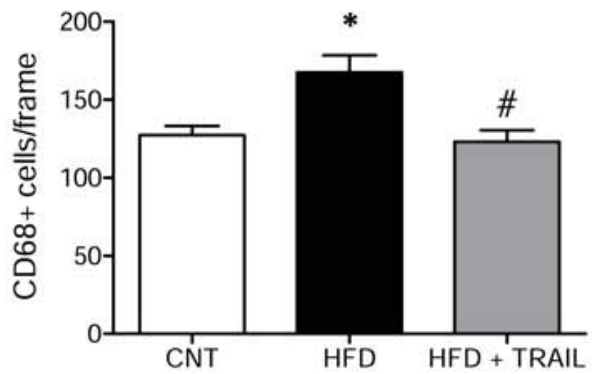

F

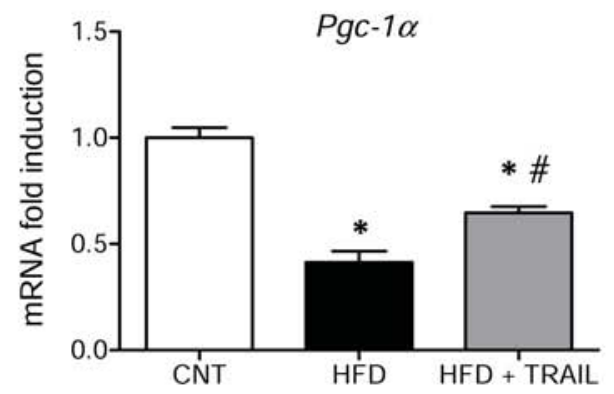

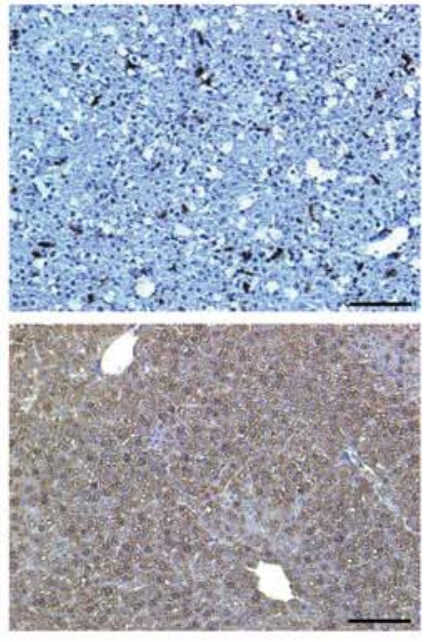

E

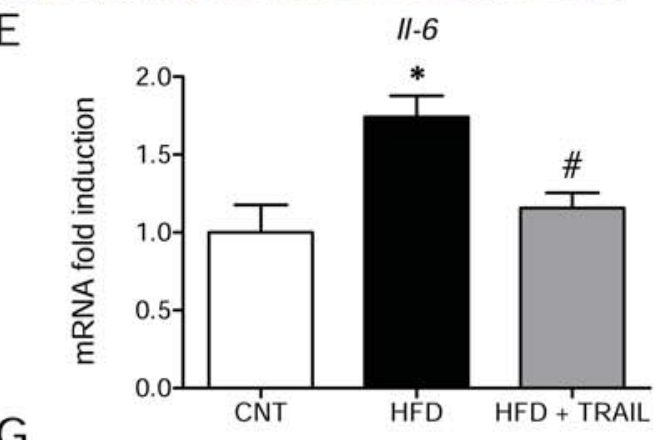

G

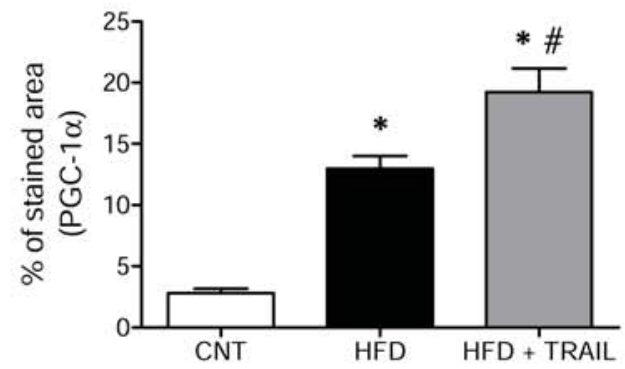


Figure 5
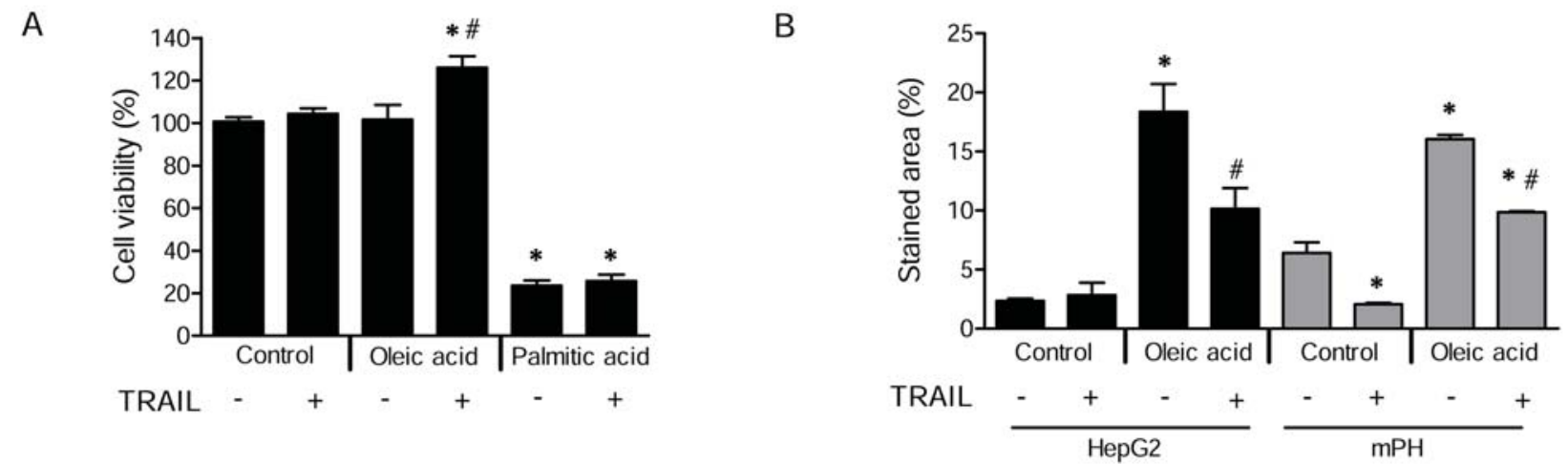

C

Control

Control + TRAIL

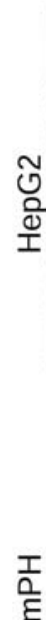
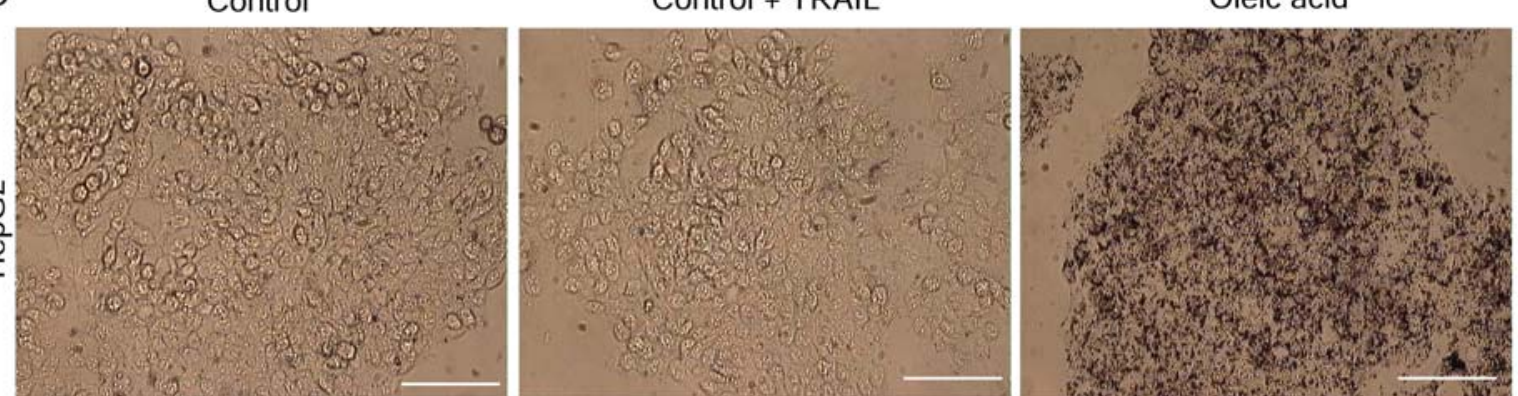

Oleic acid + TRAIL
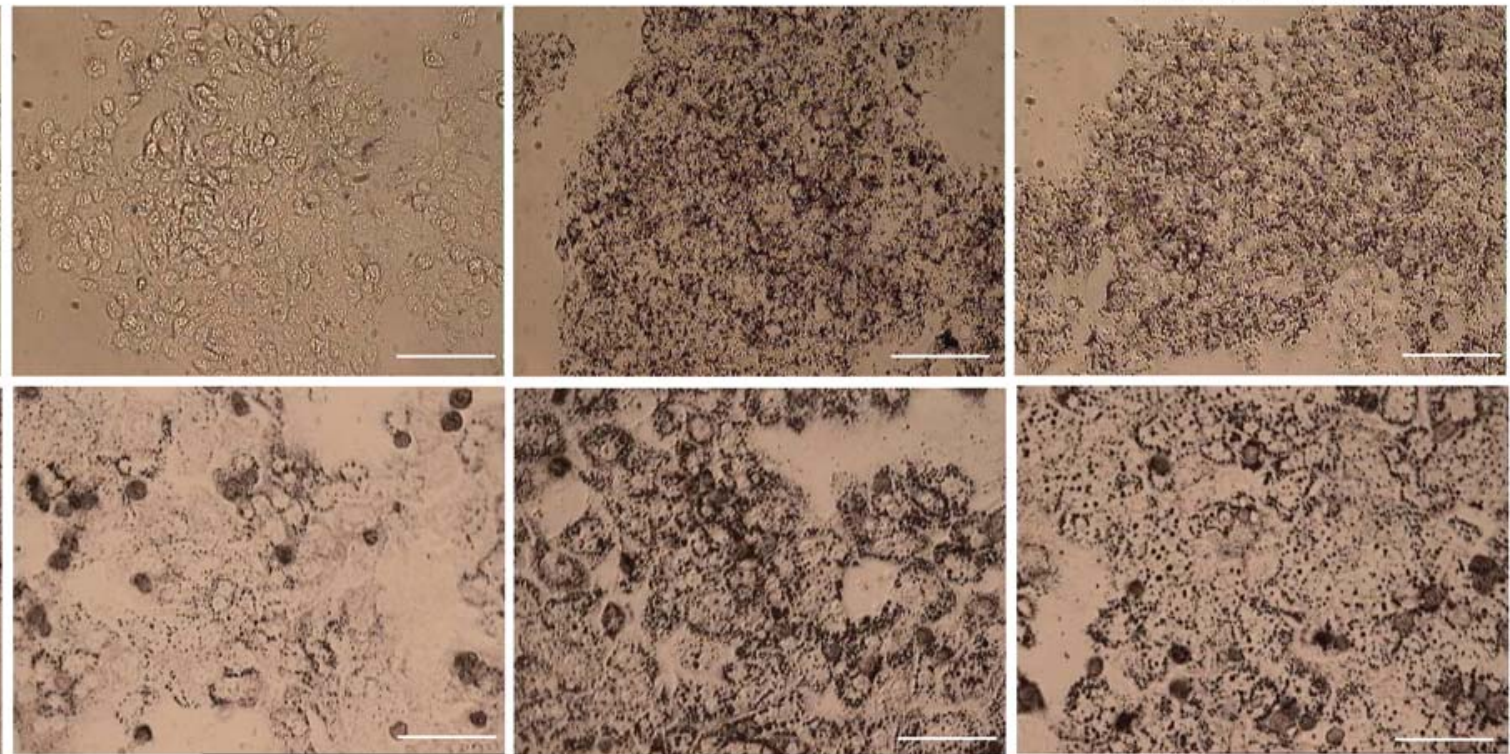
Figure 6
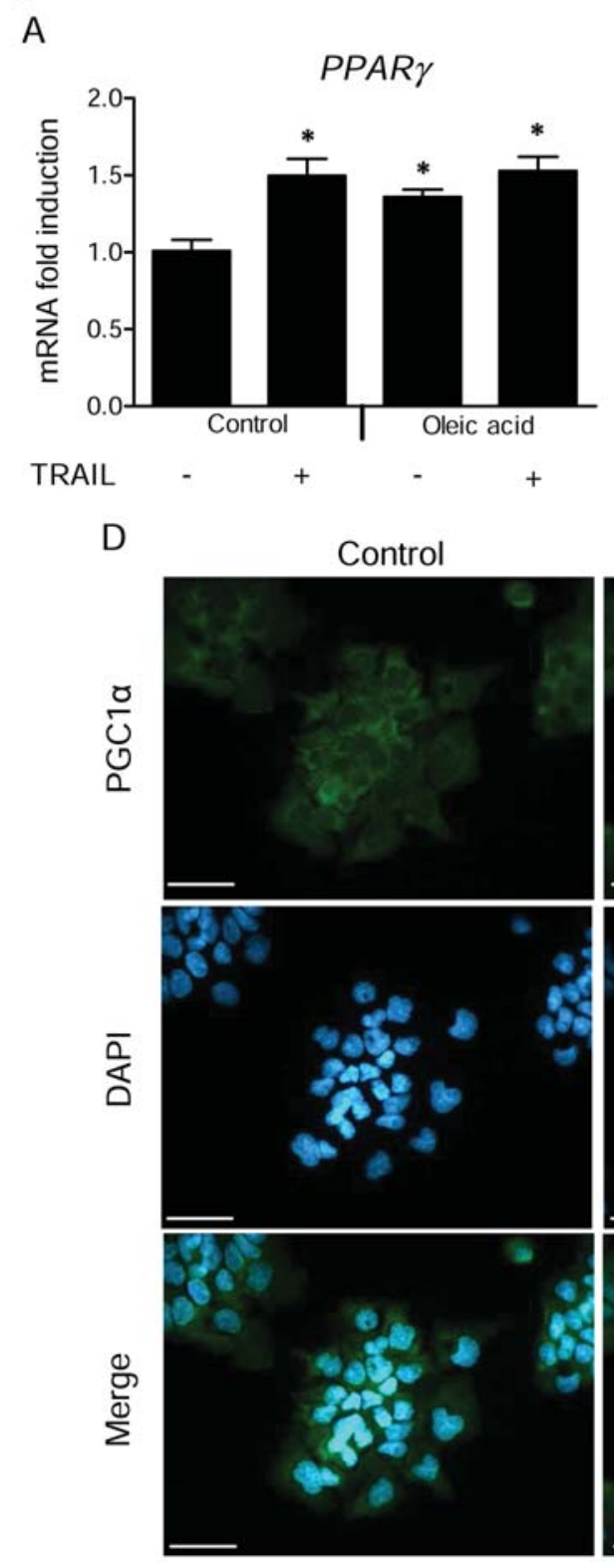

B

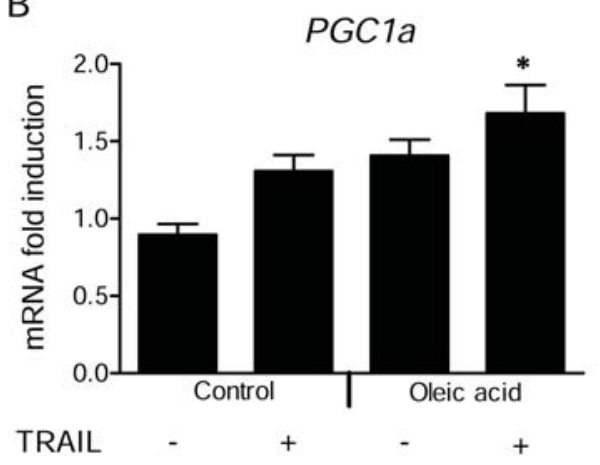

Control + TRAIL

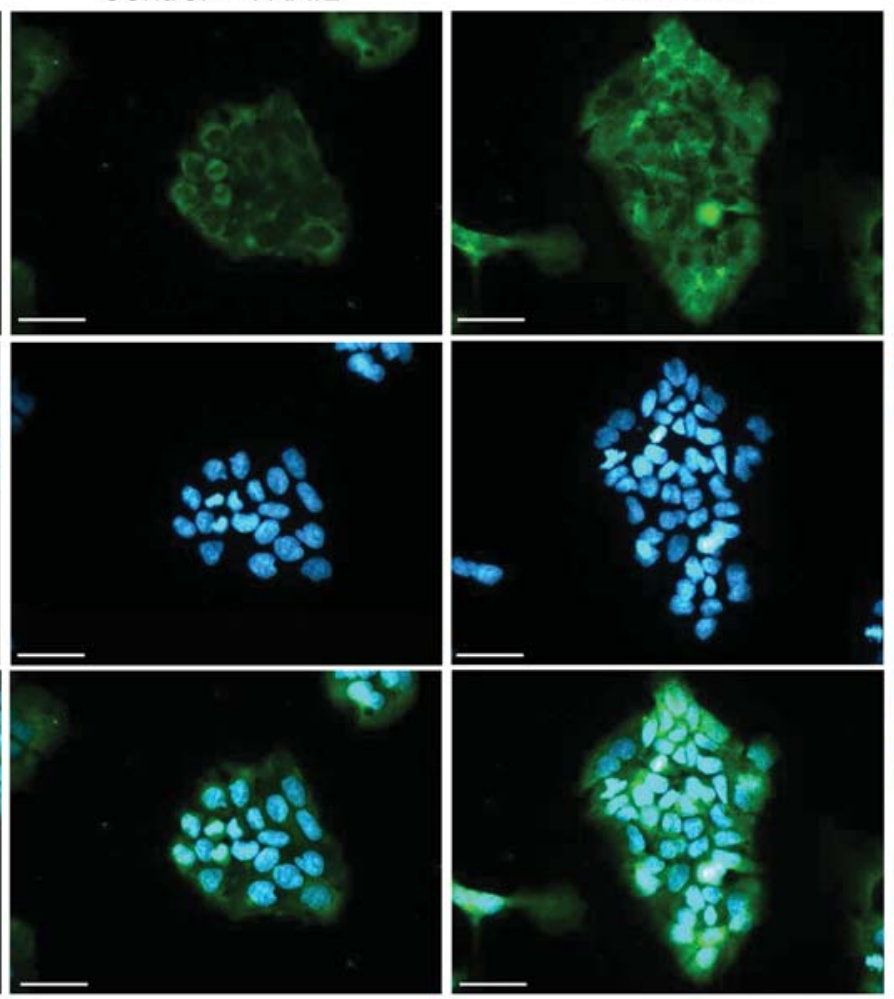

C

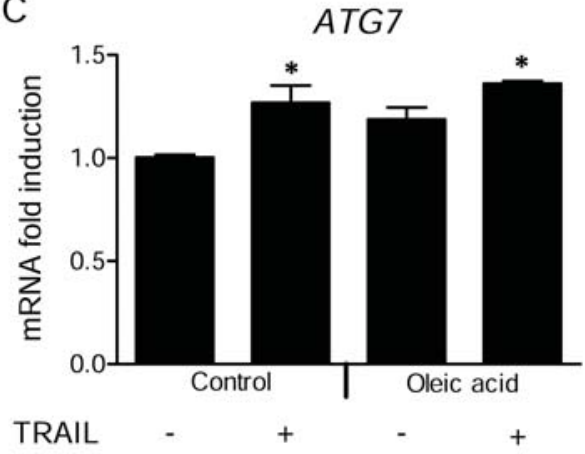

Oleic acid + TRAIL

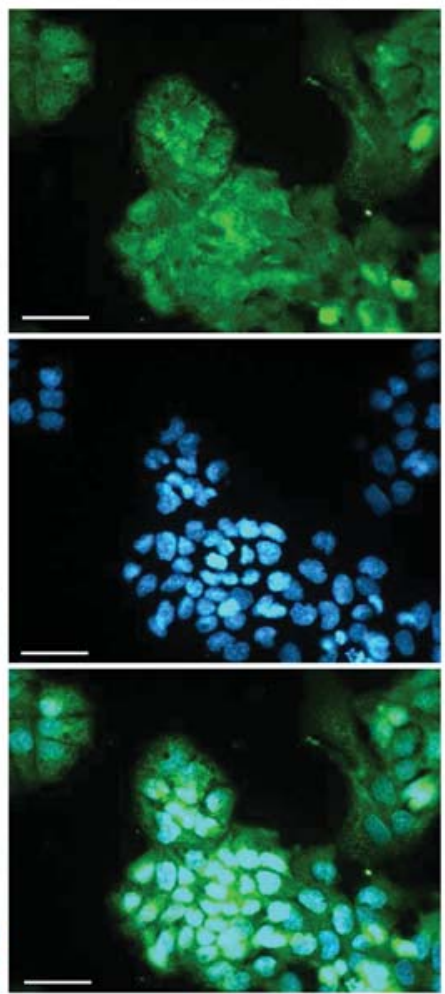




\section{Supplementary Materials and Methods}

\section{Recombinant human TRAIL (rhTRAIL) preparation}

Recombinant soluble human TRAIL (His6-tagged TRAIL) was produced in bacteria as described by MacFarlane (1997) and purified by affinity chromatography on Ni2+ affinity resin (Qiagen, Hilden, Germany). Determination of total protein concentration in the fractions collected after dialysis was performed using a bicinchoninic protein assay with bovine serum albumin as the standard, accordingly to the manufacturer's instructions (Thermo Fisher Scientific Inc., Rockford, USA). TRAIL concentration was then quantified by ELISA (R\&D Systems, Minneapolis, Minn., USA; sensitivity: $2.9 \mathrm{pg} / \mathrm{ml}$; intra- and interassay CV were 3.9 and $6 \%$, respectively) in duplicate samples. Selected samples were run in each ELISA plate as internal controls to confirm the reproducibility of the determinations over time. The functional activity of each TRAIL preparation was tested on the TRAIL-sensitive HL60 cell line by evaluating cell viability and apoptosis after treatment of the cells with serial dilutions of each preparation. Finally, purified TRAIL batches were tested for the absence of endotoxin by using the ToxinSensor chromogenic LAL endotoxin assay kit (GenScript, Piscataway, $\mathrm{NJ}$ ) and stored at $-80^{\circ} \mathrm{C}$ in single use aliquots.

\section{Labeling of rhTRAIL}

Purified rhTRAIL was labeled with N-hydroxisuccinimide ester of the cyanine 5.5 (Amersham Biosciences; FluorolinkCy5.5 Monofunctional Dye 5-pack) to form TRAIL-Cy5.5. A freshly prepared solution of dye $(0.05 \mathrm{mg} / \mathrm{mL})$ in $0.1 \mathrm{M}$ sodium carbonate buffer $\mathrm{pH} 8$ was added to rhTRAIL (1 $\mathrm{mg} / \mathrm{mL})$ in phosphate buffer (vol/vol 1:1). The reagents were incubated by gently shaking for 1 hour at room temperature. Excess unconjugated dye was removed by overnight dialysis against phosphate buffer $\mathrm{pH}$ 7.4.

Triglyceride measurement with the Beckman Coulter AU5800 analyzer 
The procedure for the determination of triglyceride concentration with the Beckman Coulter AU5800 analyzer is based on a series of coupled enzymatic reactions. The triglyceride in the sample are hydrolyzed by a combinantion of microbial lipases to give glycerol and fatty acids. The glycerol is phosphorylated by ATP in the presence of glycerol kinase to produce glycerol-3phosphate. The glycerol-3-phosphate is oxidized by molecular oxygen in the presence of glycerol phosphate oxidase to produce hydrogen peroxide $\left(\mathrm{H}_{2} \mathrm{O}_{2}\right)$ and dihydroxyacetone phosphate. The formed $\mathrm{H}_{2} \mathrm{O}_{2}$ reacts with 4-aminophenazone and N,N-bis(4-sulfobutyl)-3,5-dimethylaniline, disodium salt (MADB) in the presence of peroxidase (POD) to produce a chromophore, which is red at $660 / 880 \mathrm{~nm}$. The increase in absorbance at $660 / 800 \mathrm{~nm}$ is proportional to the triglyceride content of the sample. 
Supplementary Table 1. Sequences of probes/primer pairs

\begin{tabular}{|c|c|}
\hline Gene & Primer pair \\
\hline \multicolumn{2}{|l|}{ Mouse } \\
\hline \multirow[t]{2}{*}{ Rps9 } & (F) 5'-GACCAGGAGCTAAAGTTGATTGGA-3' \\
\hline & (R) 5'-TCTTGGCCAGGGTAAACTTGA-3' \\
\hline \multirow[t]{2}{*}{ Fas } & (F) 5'-TCGTGATGAACGTGTACCGG-3' \\
\hline & (R) 5'- GGGTGAGGACGTTTACAAAG-3' \\
\hline \multirow[t]{2}{*}{ Srebp1a } & (F) 5'-ATGGACGAGCTGGCCTTCG-3' \\
\hline & (R) 5'- TGTTGATGAGCTGGAGCATGTCTTC-3' \\
\hline \multirow[t]{2}{*}{ Srebp1c } & (F) 5'-ATGGATTGCACATTTGAAGACATGCT-3' \\
\hline & (R) 5'- CCTGTGTCCCCTGTCTCAC-3' \\
\hline \multirow[t]{2}{*}{ Aox } & (F) 5'-TCACGTTTACCCCGGC-3' \\
\hline & (R) 5'- CAAGTACGACACCATACCAC-3' \\
\hline \multirow[t]{2}{*}{ Cpt1a } & (F) 5'-CCAAGTATCTGGCAGTCGA-3' \\
\hline & (R) 5'-CGCCACAGGACACATAGT-3' \\
\hline \multirow[t]{2}{*}{ Ppara } & (F) 5'-TCAAGGTGTGGCCCAAGGTTA-3' \\
\hline & (R) 5'-CGAATGTTCTCAGAAGCCAGCTC-3' \\
\hline \multirow[t]{2}{*}{ Irs2 } & (F) 5'-GACTTCCTGTCCCATCACTTG-3' \\
\hline & (R) 5'-TTTCAACATGGCGGCGA-3' \\
\hline \multirow[t]{2}{*}{ Pepck } & (F) 5'-CCATCCCAACTCGAGATTCTG-3' \\
\hline & (R) 5'- CTGAGGGCTTCATAGACAAGG-3' \\
\hline \multirow[t]{2}{*}{ Ppary } & (F) 5'-TGTCGGTTTCAGAAGTGCCTTG-3' \\
\hline & (R) 5'-TTCAGCTGGTCGATATCACTGGAG-3' \\
\hline \multirow[t]{2}{*}{ Hnf4 } & (F) 5'-CAAGAGGTCCATGGTGTTTAAGG-3' \\
\hline & (R) 5'-CGGCTCATCTCCGCTAGCT-3' \\
\hline \multirow[t]{2}{*}{ Cit Synt } & (F) 5'-CAAGCAGCAACATGGGAAGA-3' \\
\hline & (R) 5'-GTCAGGATCAAGAACCGAAGTCT-3' \\
\hline \multirow[t]{2}{*}{$P g c-1 \alpha$} & (F) 5'-TGATGTGAATGACTTGGATACAGACA-3' \\
\hline & (R) 5'- GCTCATTGTTGTACTGGTTGGATATG-3' \\
\hline \multirow[t]{2}{*}{ Ucp2 } & (F) 5'-GCCTCTGGAAAGGGAGTTCTC-3' \\
\hline & (R) 5'- ACCAGCTCAGCACAGTTGACA-3' \\
\hline \multirow[t]{2}{*}{ gp91phox } & 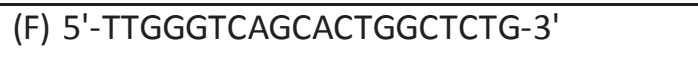 \\
\hline & (R) 5'-TGGCGGTGTGCAGTGCTATC-3' \\
\hline \multirow[t]{2}{*}{$11-6$} & (F) 5'-ACCAGAGGAAATTTTCAATAGGC-3' \\
\hline & (R) 5'- TGATGCACTTGCAGAAAACA-3' \\
\hline \multirow[t]{2}{*}{ Tnf $\alpha$} & (F) 5'-AAGCCTGTAGCCCACGTCGTA-3' \\
\hline & (R) 5'-GGCACCACTAGTTGGTTGTCTTTGG-3' \\
\hline \multirow[t]{2}{*}{$\operatorname{Atg} 7$} & (F) 5'-TGCCTATGATGATCTGTGTC-3' \\
\hline & (R) 5'-CACCAACTGTTATCTTTGTCC-3' \\
\hline \multirow[t]{2}{*}{ Pln5 } & (F) 5'-TCTCGCCTATGAACACTCTTTG-3' \\
\hline & (R) 5'-GGGATGGAAAGTAGGGCTAG-3' \\
\hline \multirow[t]{2}{*}{ Sirt-1 } & (F) 5'-TGTGAAGTTACTGCAGGAGTG-3' \\
\hline & (R) 5'-CAAGGCGAGCATAGATACCG-3' \\
\hline Human & \\
\hline
\end{tabular}




\begin{tabular}{|l|l|}
\hline$R P L 27$ & $\begin{array}{l}\text { (R) 5'-TGTCCTGGCTGGACGCTACT-3' } \\
\text { (F) 5'-CTGAGGTGCCATCATCAATGTT-3' }\end{array}$ \\
\hline$D R 4$ & (F) 5'-CACAAGACCTTCAAGTTTGTCG-3' \\
& (R) 5'-TGGACACAACTCTCCCAAAG-3' \\
\hline$D R 5$ & (F) 5'-ATCGTGAGTATCTTGCAGCC-3' \\
& (R) 5'-TGAGACCTTTCAGCTTCTGC-3' \\
\hline$D c R 1$ & (F) 5'-GATTACACCAACGCTTCCAAC-3' \\
& (R) 5'-TGCCTTCTTTACACTGACACAC-3' \\
\hline$D c R 2$ & (F) 5'-GTGGTTGTGGTTGGCTTTTC-3' \\
& (R) 5'-CAGGAACTCGTGAAGGACATG-3' \\
\hline$P P A R \gamma$ & (F) 5'-AAGGCGAGGGCGATCTTG-3' \\
& (R) 5'-CCCATCATTAAGGAATTCATGTCA-3' \\
\hline$P G C-1 \alpha$ & (F) 5'-AAACAGCAGCAGAGACAAATGC-3' \\
& (R) 5'-TTGGTTTGGCTTGTAAGTGTTGTG-3' \\
\hline ATG7 & (F) 5'-TCGAAAGCCATGATGTCGTCTT-3' \\
& (R) 5'-CCAAAGCAGCATTGATGACCA-3' \\
\hline CXCL8 & (F) 5'-TTCCTGATTTCTGCAGCTCT-3' \\
& (R) 5'-TGTCTTTATGCACTGACATC-3' \\
\hline TNFa & (F) 5'-CAGGGACCTCTCTCTAATCA-3' \\
& (R) 5'-GGCTACAGGCTTGTCACTCG-3' \\
\hline Gene & Probe/Primer pair \\
\hline Mouse & \\
\hline Mcp1 & (P) FAM-5'-TCCCTGTCATGCTTCTGGGCCTGT-3'-TAMRA \\
\hline & (F) 5'-CTTCCTCCACCACCATGCA-3' \\
\hline (R) 5'-CCAGCCGGCAACTGTGA-3' \\
\hline
\end{tabular}




\section{Supplementary Figure Legends}

Supplementary Figure 1. Pancreatic beta cell density and mass. (A) Pancreatic beta cell density as assessed by percentage of islet area positive for insulin (brown staining); (B) Pancreatic beta cell mass was estimated by multiplying the mean density of staining for insulin in the islet section by the mean islet area per area of pancreas. This was adjusted for the pancreatic wet weight for individual animals and expressed as fold changes relative to CNT mice.

Supplementary Figure 2. Gene expression in in vivo and in vitro studies. (A) Liver, white adipose tissue (WAT), and skeletal muscle mRNA expression of Ppary, Pgc-1 $\alpha$, and Atg7. PPAR $\gamma$ is for peroxisome proliferator-activated receptor- $\gamma$; PGC- $1 \alpha$ is for peroxisome proliferator-activated receptor- $\gamma$ coactivator-1 alpha; ATG7 is for autophagy-related protein 7. mRNA expression is reported as fold induction standardized to the mRNA expression in CNT mice. Results are presented as mean \pm SEM; $*$ p $<0.05$ vs CNT; \# $<<0.05$ vs HFD. (B-C) HepG2 cell mRNA expression of TRAIL receptors (DR4, DR5, DcR1, DcR2) and proinflammatory molecules (CXCL8 and TNF $\alpha$ ). DR is for death receptor; DcR is for decoy receptor; CXCL8 is for chemokine (C-X-C motif) ligand 8 . Cells were treated with oleic acid $(250 \mu \mathrm{M})$ in presence or absence of rhTRAIL (1 $\mathrm{ng} / \mathrm{mL}$ ) for 6 hours. For primer pairs see Supplementary Table 1. 
Supplementary Figure 1

A

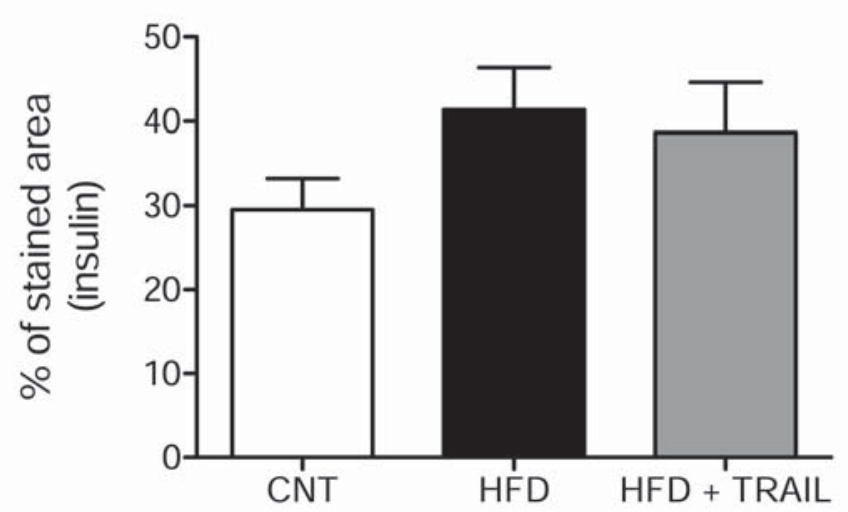

B

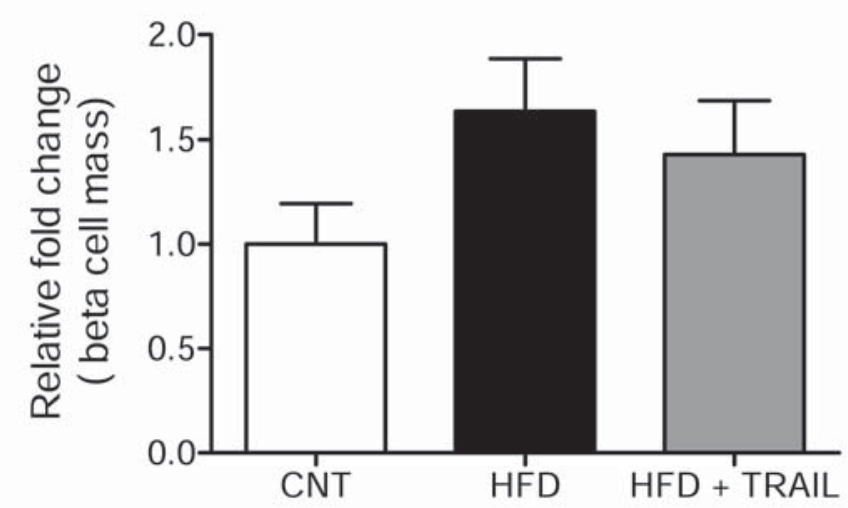


Supplementary Figure 2
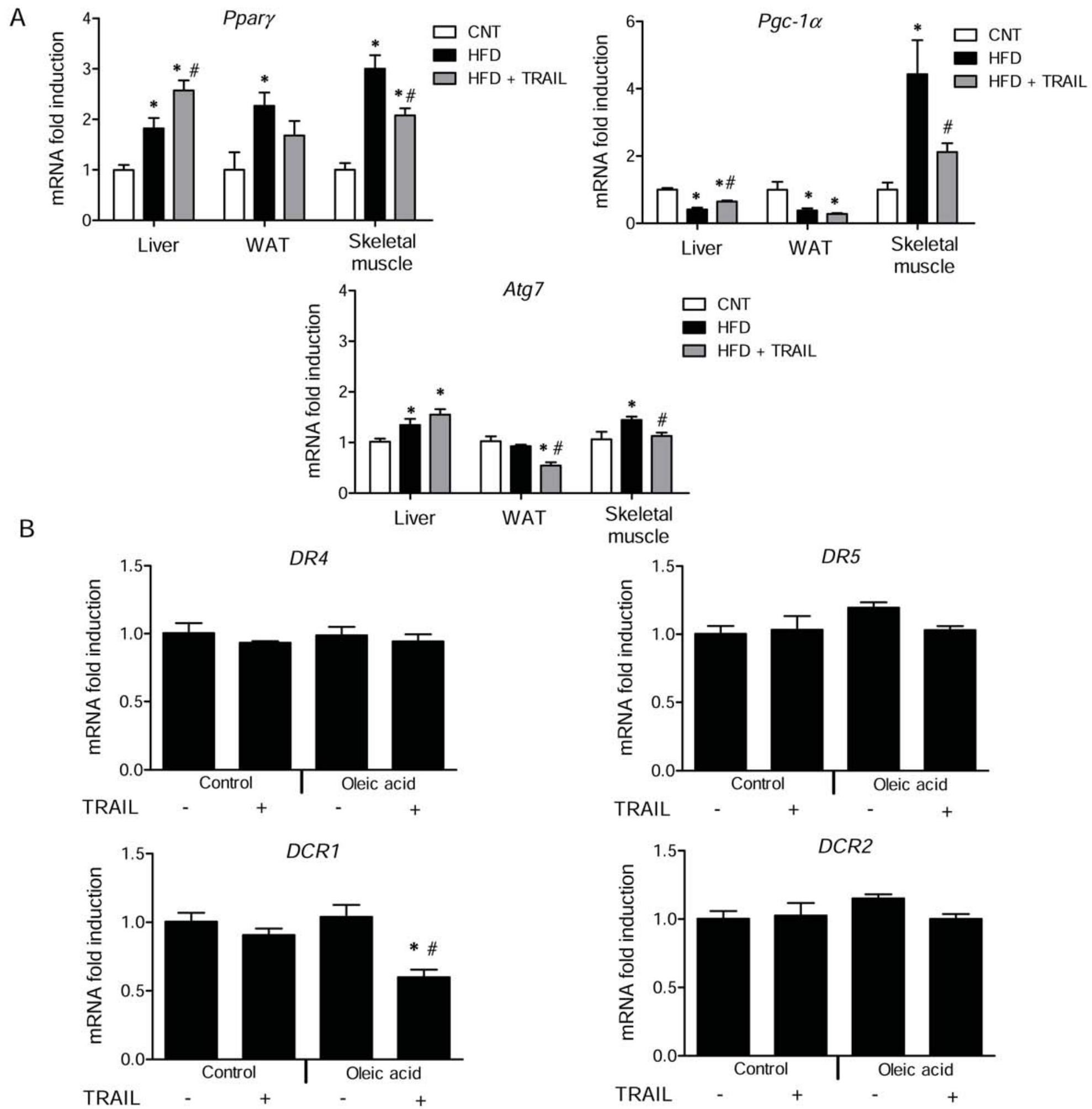

C
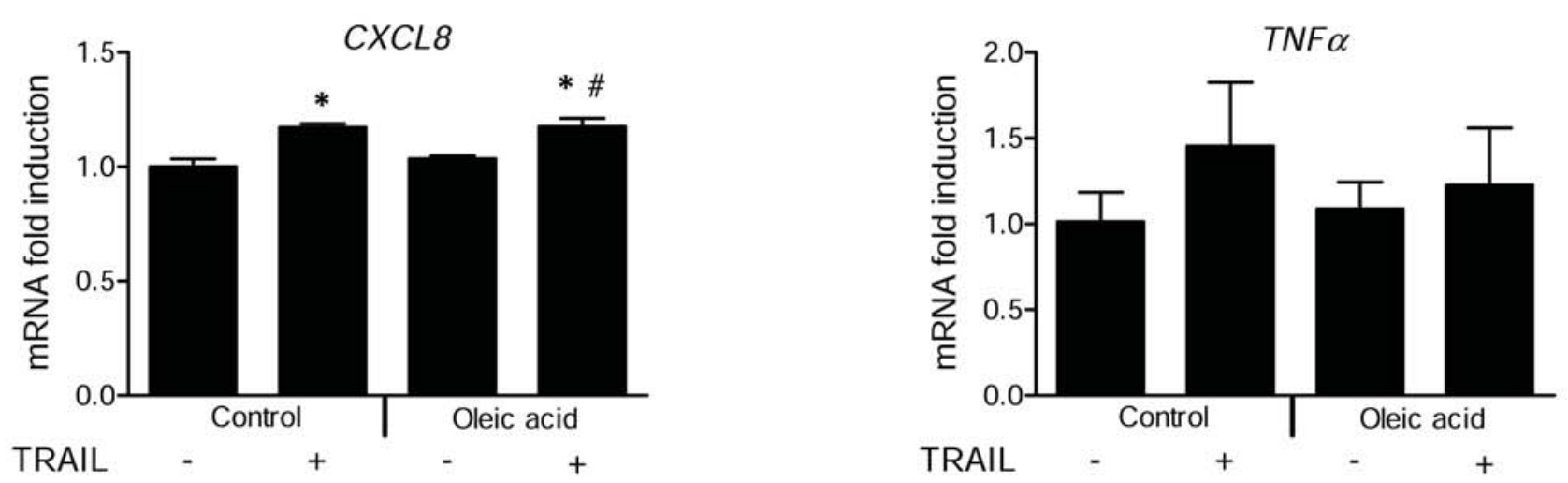